Utah State University

DigitalCommons@USU

Mechanical and Aerospace Engineering Student Mechanical and Aerospace Engineering Student Publications and Presentations

8-2020

\title{
Minimising Induced Drag with Weight Distribution, Lift Distribution, Wingspan, and Wing-Structure Weight
}

Warren F. Phillips

Utah State University, wfphillips@engineering.usu.edu

Douglas F. Hunsaker

Utah State University, doug.hunsaker@usu.edu

Jeffrey D. Taylor

Utah State University, jeffdtaylor3891@gmail.com

Follow this and additional works at: https://digitalcommons.usu.edu/mae_stures

Part of the Mechanical Engineering Commons

\section{Recommended Citation}

Phillips, W. F., Hunsaker, D. F., and Taylor, J. D., "Minimising Induced Drag with Lift Distribution, Wingspan, and Wing Weight," The Aeronautical Journal, Vol. 124, No. 1278, August 2020, pp. 1208-1235.

doi:10.1017/aer.2020.24

This Article is brought to you for free and open access by the Mechanical and Aerospace Engineering Student Research at DigitalCommons@USU. It has been accepted for inclusion in Mechanical and Aerospace Engineering Student Publications and Presentations by an authorized administrator of DigitalCommons@USU. For more information, please contact digitalcommons@usu.edu.

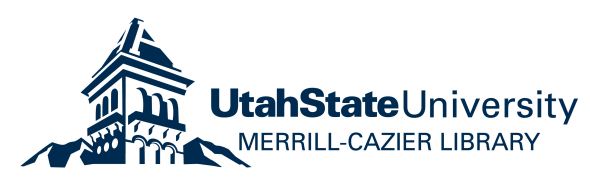




\title{
Minimizing Induced Drag with Weight Distribution, Lift Distribution, Wingspan, and Wing-Structure Weight
}

\author{
W. F. Phillips, ${ }^{*}$ D. F. Hunsaker, ${ }^{\dagger}$ and J. D. Taylor ${ }^{\ddagger}$ \\ Utah State University, Logan, Utah 84322-4130
}

Because the wing-structure weight required to support the critical wing section bending moments is a function of wingspan, net weight, weight distribution, and lift distribution, there exists an optimum wingspan and wing-structure weight for any fixed net weight, weight distribution, and lift distribution, which minimizes the induced drag in steady level flight. Analytic solutions for the optimum wingspan and wing-structure weight are presented for rectangular wings with four different sets of design constraints. These design constraints are fixed lift distribution and net weight combined with 1) fixed maximum stress and wing loading, 2) fixed maximum deflection and wing loading, 3) fixed maximum stress and stall speed, and 4) fixed maximum deflection and stall speed. For each of these analytic solutions, the optimum wing-structure weight is found to depend only on the net weight, independent of the arbitrary fixed lift distribution. Analytic solutions for optimum weight and lift distributions are also presented for the same four sets of design constraints. Depending on the design constraints, the optimum lift distribution can differ significantly from the elliptic lift distribution. Solutions for two example wing designs are presented, which demonstrate how the induced drag varies with lift distribution, wingspan, and wing-structure weight in the design space near the optimum solution. Although the analytic solutions presented here are restricted to rectangular wings, these solutions provide excellent test cases for verifying numerical algorithms used for more general multidisciplinary analysis and optimization.

\section{Nomenclature}

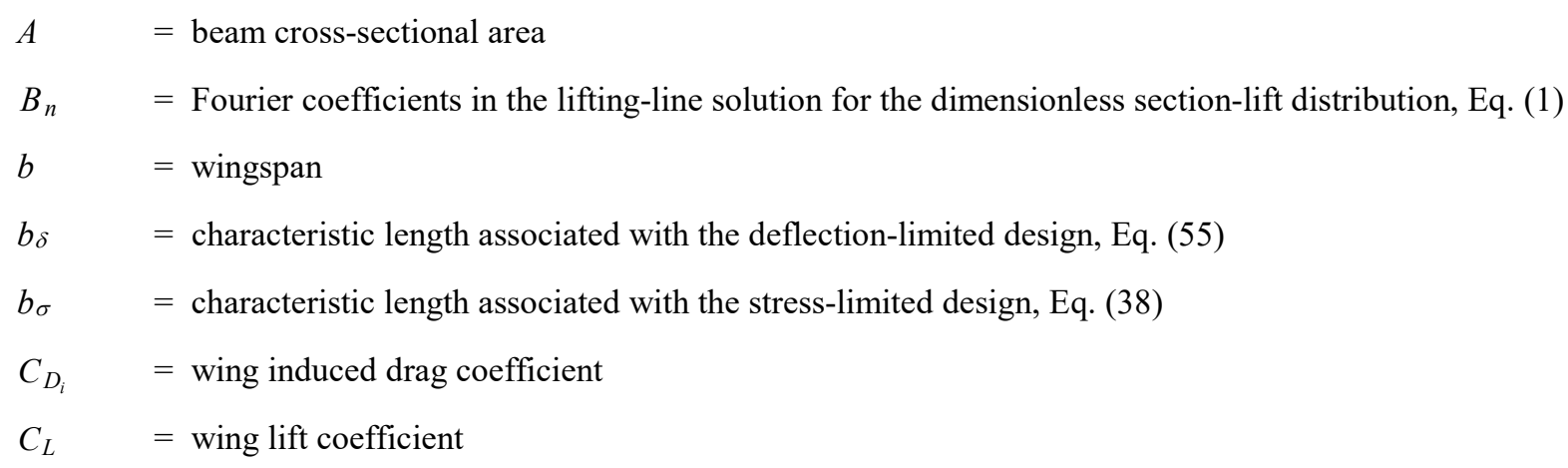

\footnotetext{
* Emeritus Professor, Mechanical and Aerospace Engineering, 4130 Old Main Hill, AIAA Senior Member.

${ }^{\dagger}$ Assistant Professor, Mechanical and Aerospace Engineering, 4130 Old Main Hill, AIAA Senior Member.

* Graduate Student, Mechanical and Aerospace Engineering, 4130 Old Main Hill, AIAA Student Member.
} 


$$
\begin{aligned}
& C_{L_{\max }} \quad=\text { wing lift coefficient at the onset of flow separation } \\
& C_{L, \alpha} \quad=\text { wing lift slope } \\
& C_{\delta} \quad=\text { shape coefficient for the deflection-limited design, Eq. (16) } \\
& C_{\sigma} \quad=\text { shape coefficient for the stress-limited design, Eq. (9) } \\
& \widetilde{C}_{L} \quad=\text { airfoil section lift coefficient } \\
& \widetilde{C}_{L_{\max }} \quad=\text { airfoil section lift coefficient at the onset of flow separation } \\
& \widetilde{C}_{L, \alpha} \quad=\text { airfoil section lift slope } \\
& c \quad=\text { local wing section chord length } \\
& c_{\text {root }}=\text { wing section chord length at the wing root } \\
& D_{i} \quad=\text { wing induced drag } \\
& E \quad=\text { modulus of elasticity of the beam material } \\
& h \quad=\text { height of the beam cross-section } \\
& I=\text { beam section moment of inertia } \\
& L \quad=\text { total wing lift } \\
& \tilde{L} \quad=\text { local wing section lift } \\
& \tilde{M}_{b} \quad=\text { local wing section bending moment } \\
& n_{a} \quad=\text { load factor, } g \\
& n_{g} \quad=\text { limiting load factor at the hard-landing design limit } \\
& n_{m} \quad=\text { limiting load factor at the maneuvering-flight design limit } \\
& S \quad=\text { wing planform area } \\
& S_{b} \quad=\text { proportionality coefficient between } \widetilde{W}_{s}(z) \text { and } \widetilde{M}_{b}(z) \text { having units of length squared } \\
& t_{\max }=\text { maximum thickness of the local airfoil section } \\
& V_{\infty} \quad=\text { freestream airspeed } \\
& V_{\text {stall }}=\text { freestream airspeed at the onset of flow separation } \\
& W \quad=\text { aircraft gross weight } \\
& W_{n} \quad=\text { aircraft net weight (i.e., } W-W_{s} \text { ) } \\
& W_{r} \quad=\text { that portion of } W_{n} \text { carried at the wing root } \\
& W_{S} \quad=\text { total weight of the wing structure required to support the wing bending moment distribution } \\
& \widetilde{W}_{n} \quad=\text { net weight of the wing per unit span (i.e., total wing weight per unit span less } \widetilde{W}_{s} \text { ) } \\
& \widetilde{W}_{S} \quad=\text { weight of the wing structure per unit span required to support the wing bending moment distribution } \\
& z \quad=\text { spanwise coordinate relative to the midspan } \\
& \gamma=\text { specific weight of the beam material } \\
& \delta_{\max } \quad=\text { maximum wing deflection }
\end{aligned}
$$




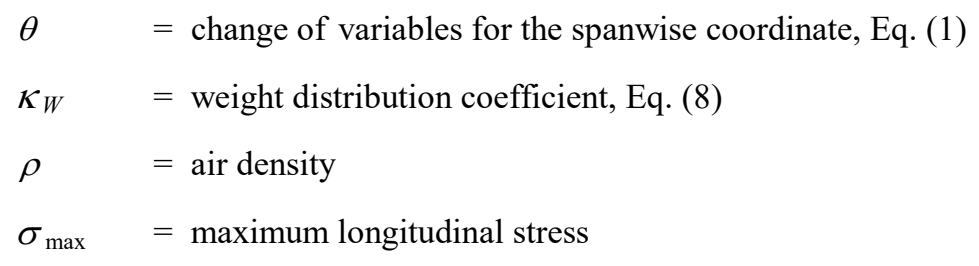

\section{Introduction}

For a wing with no sweep or dihedral immersed in a uniform flow, Prandtl's classical lifting-line theory $[1,2]$ relates the section-lift distribution to the chord-length and aerodynamic-angle-of-attack distributions. Additionally, for any given wing planform, Prandtl's lifting-line theory can be used to obtain the geometric- and/or aerodynamictwist distribution required to produce any desired section-lift distribution [3-8]. With Prandtl's lifting-line theory, an arbitrary spanwise section-lift distribution is typically written as a Fourier sine series. Although this Fourier series has been written in different forms, here we shall use the form [9]

$$
\frac{b \widetilde{L}(\theta)}{L}=\frac{4}{\pi}\left[\sin (\theta)+\sum_{n=2}^{\infty} B_{n} \sin (n \theta)\right] ; \quad \theta \equiv \cos ^{-1}(-2 z / b)
$$

The classical lifting-line solution for induced drag can be written in terms of the Fourier coefficients in Eq. (1). In steady level flight, the total wing lift $L$ must equal the gross weight $W$. Thus, the lifting-line solution for the induced drag in steady level flight can be written as [9]

$$
D_{i}=\frac{2(W / b)^{2}}{\pi \rho V_{\infty}^{2}}\left(1+\sum_{n=2}^{\infty} n B_{n}^{2}\right)
$$

For a fixed ratio of gross weight to wingspan, this induced drag is minimized with the section-lift distribution having $B_{n}=0$ for all $n \geq 2$, which yields the well-known elliptic lift distribution introduced by Prandtl [2]. However, as pointed out by Prandtl [10], when designing a wing to minimize the induced drag in steady level flight, imposing the constraints of fixed gross weight and wingspan does not yield an absolute minimum in the induced drag. For any given lift distribution, weight distribution, and wing structural design, there is an optimum wingspan for minimizing the induced drag, which is based on the tradeoff between wingspan and wing-structure weight. Furthermore, any section-lift distribution that produces lower wing section bending moments than those produced by the elliptic lift distribution will allow the implementation of a larger wingspan for a given wing-structure weight. Because the wing-structure weight required to support the critical wing section bending moments is a function of wingspan, net weight, weight distribution, and lift distribution, designing a wing to minimize the induced drag in steady level flight requires solving a variational problem in which the weight distribution, lift distribution, wingspan, and wing-structure weight are all allowed to vary.

The variational problem associated with designing a wing that yields an absolute minimum in induced drag was first considered by Prandtl in 1933 [10]. In this paper, Prandtl obtained an analytic solution for the fixed lift 
distribution that minimizes the induced drag under the constraints of fixed gross lift and fixed moment of inertia of gross lift, but with no constraint placed on the wingspan. Prandtl's foundational 1933 paper was originally published in German. However, a translation of that paper was recently published in English [11]. Prandtl's 1933 solution [10] for minimizing induced drag under these constraints yields the dimensionless section-lift distribution [9]

$$
\frac{b \widetilde{L}(\theta)}{L}=\frac{4}{\pi}\left[\sin (\theta)-\frac{1}{3} \sin (3 \theta)\right]
$$

By comparison with Eq. (1), Eq. (3) requires $B_{3}=-1 / 3$ and $B_{n}=0$ for all $n \neq 3$. Using these Fourier coefficients in Eq. (2) yields the induced drag in steady level flight for Prandtl's 1933 lift distribution, i.e.,

$$
D_{i}=\frac{8(W / b)^{2}}{3 \pi \rho V_{\infty}^{2}}
$$

Comparing Eqs. (2) and (4), we see that Prandtl's 1933 lift distribution produces more induced drag than the elliptic lift distribution if the weight and wingspan are fixed. However, under the constraints of Prandtl's assumptions $[10,11]$, including that the wing-structure weight is proportional to the bending moments, Prandtl's 1933 lift distribution allows a $22.5 \%$ increase in the wingspan over that allowed by the elliptic lift distribution for the same gross weight. Accounting for this wingspan increase in Eq. (4), it can be shown that Prandtl's 1933 lift distribution produces $11.1 \%$ less induced drag than the elliptic lift distribution for the same gross weight [9-11]. However, it should be emphasized that Prandtl made no claim that the lift distribution in Eq. (3) yields an absolute minimum in induced drag for any specific case of a physical wing [10,11]. He claimed only that this lift distribution minimizes induced drag under the particular constraints of fixed gross lift and fixed moment of inertia of gross lift.

Phillips, Hunsaker, and Joo [9] have shown that Prandtl's 1933 lift distribution also yields a minimum in induced drag for the stress-limited design of a rectangular wing with fixed weight and chord-length constraints combined with the weight distribution constraint given by

$$
\widetilde{W}_{n}(z)=\left(W-W_{r}\right) \frac{\widetilde{L}(z)}{L}-\widetilde{W}_{s}(z)
$$

Equation (5) alone does not completely specify the weight distribution $\widetilde{W}_{n}(z)$. It simply provides one relation between the five design parameters, $\widetilde{W}_{n}(z), W, W_{r}, \widetilde{W}_{s}(z)$, and $\widetilde{L}(z) / L$. Equation (5) could be applied in the early stages of preliminary design, if no conflicting constraint is placed on the weight distribution. However, $\widetilde{W}_{n}(z)$ cannot be evaluated from Eq. (5) until the other four parameters in Eq. (5) have been determined from other means.

The wing structure at each section of a wing must be sufficient to support the wing bending-moment distribution at the design limits for both maneuvering flight and a hard landing. Because the wing bending-moment distribution depends on the weight distribution, the variational problem associated with minimizing induced drag for an arbitrarily specified weight distribution, with no constraint placed on the wingspan, will most likely need to be 
solved numerically. However, the application of Eq. (5) substantially reduces the constraining wing bendingmoment distribution and simplifies the integration of the governing equations such that the wing-structure weight can be found analytically [9]. It has also been shown that applying Eq. (5) along with the additional weight distribution constraint given by

$$
W_{r}=\frac{n_{g}-1}{n_{m}+n_{g}} W
$$

gives the optimum weight distribution, which minimizes the bending moment required for the constraining design limit [9]. Therefore, in this paper, we will use the weight distribution described by Eqs. (5) and (6) to permit analytic evaluation of the wing-structure weight and to minimize the wing bending moments. As will be shown later, Eqs. (5) and (6) produce weight distributions that exhibit reasonable trends. However, it should be noted that the wing weight distribution is typically designed with additional constraints to those used in obtaining Eqs. (5) and (6). Thus, the weight distribution described by Eqs. (5) and (6) may not always be practical.

Using both Eqs. (5) and (6) yields a bending-moment distribution for the hard-landing design limit that is exactly the negative of that required for the maneuvering-flight design limit. If $W_{r}$ is larger than the value given by Eq. (6), then maneuvering flight provides the structural design limit; and if $W_{r}$ is less than the value given by Eq. (6), the hard landing provides the structural design limit. In any case, if the weight distribution in Eq. (5) is used and the lift is positive over the entire semispan, the structural design limit for the wing bending moment can be written as [9]

$$
\left|\widetilde{M}_{b}(z)\right|=\kappa_{W} W_{r} \int_{z^{\prime}=z}^{b / 2} \frac{\widetilde{L}\left(z^{\prime}\right)}{L}\left(z^{\prime}-z\right) d z^{\prime}, \text { for } z \geq 0
$$

where

$$
\kappa_{W} \equiv \begin{cases}n_{m}, & W_{r} \geq \frac{n_{g}-1}{n_{m}+n_{g}} W \\ \left(n_{g}-1\right) \frac{W}{W_{r}}-n_{g}, & W_{r}<\frac{n_{g}-1}{n_{m}+n_{g}} W\end{cases}
$$

If the wing section bending moment is supported by any vertically symmetric beam, for a fixed maximum-stress constraint with spanwise-symmetric wing loading, the total weight of the wing structure required to support the bending-moment distribution at the design limit can be expressed as [9]

$$
W_{s}=2 \int_{z=0}^{b / 2} \frac{\left|\tilde{M}_{b}(z)\right|}{S_{b}(z)} d z ; \quad S_{b}(z) \equiv \frac{C_{\sigma}\left(t_{\max } / c\right) c(z) \sigma_{\max }}{\gamma}, \quad C_{\sigma} \equiv \frac{2 I\left(h / t_{\max }\right)}{A h^{2}}
$$

Equations for computing values of $C_{\sigma}$ for some common beam cross-sections are presented in Ref. [9].

We see from Eq. (9) that, for any spanwise-symmetric wing loading, the weight of the wing structure required to support a maximum-stress constraint is proportional to the integral of the bending-moment distribution divided by 
the chord-length distribution. Because, in the development of his 1933 lift distribution, Prandtl assumed a proportionality coefficient between $\tilde{M}_{b}$ and $\tilde{W}_{s}$ that is independent of $z$ [10], the resulting minimum-drag analysis may not apply to the stress-limited design of a wing with a chord length and thickness that vary with the spanwise coordinate. However, Prandtl's 1933 minimum-drag analysis could be applied to the stress-limited design of a rectangular wing with the weight distribution specified by Eq. (5).

Approaches similar to that of Prandtl have been taken by others to find analytic solutions to this complex, variational, optimization problem. For example, Jones [12] looked at minimizing the induced drag for a given lift and root bending moment. Later, Jones and Lasinski [13] added a constraint on the integrated bending moment and included the effects of winglets. Klein and Viswanathan have also considered the problem of a given total lift and root bending moment [14] and have extended the theory to include a given wing-structure weight [15]. More recently, Phillips, Hunsaker, and Joo [9] have presented both stress-limited and deflection-limited solutions for minimizing induced drag on a rectangular wing with fixed weight and wing-loading constraints. The work of Phillips, Hunsaker, and Joo [9] has also been extended to account for the effects of wing taper by Taylor and Hunsaker [16]. Other relevant publications include [17-28].

Combining Eqs. (1), (7), and (9), Phillips, Hunsaker, and Joo [9] have shown that, for the stress-limited design of a rectangular wing with any all-positive spanwise-symmetric lift distribution and the weight distribution specified by Eq. (5), the required weight of the wing structure is given by [9]

$$
W_{s}=\frac{\kappa_{W} W_{r} b^{2}}{32 S_{b}}\left(1+B_{3}\right)
$$

Notice from Eq. (2) that all Fourier coefficients $B_{n}$ make a positive contribution to the induced drag. However, we see from Eq. (10) that only $B_{3}$ contributes to the required structure weight of a rectangular wing with any all-positive spanwise-symmetric lift distribution and the weight distribution specified by Eq. (5).

For the stress-limited design of a rectangular wing with the weight distribution specified by Eq. (5) and any allpositive spanwise-symmetric lift distribution, the total weight of the wing structure required to support the bendingmoment distribution at the design limit is given by [9]

$$
W_{s}=\frac{\gamma(W / S)}{32 C_{\sigma}\left(t_{\max } / c\right) \sigma_{\max }} \frac{\kappa_{W} W_{r} b^{3}}{W}\left(1+B_{3}\right)
$$

Under the constraints of a fixed lift distribution, fixed gross weight, fixed maximum stress, and fixed wing loading, the induced drag on a rectangular wing is minimized using a lift distribution having

$$
B_{3}=-3 / 8+\sqrt{9 / 64-1 / 12} ; \quad B_{n}=0, \text { for } n \neq 3
$$

which yields the optimum results 


$$
\begin{gathered}
\frac{b \tilde{L}(\theta)}{L}=\frac{4}{\pi}[\sin (\theta)-0.13564322 \sin (3 \theta)] \\
b=\sqrt[3]{\frac{32 C_{\sigma}\left(t_{\max } / c\right) \sigma_{\max }}{0.86435678 \gamma(W / S)} \frac{W_{S} W}{\kappa_{W} W_{r}}} \\
D_{i}=\frac{2.11039450}{\pi \rho V_{\infty}^{2}}\left[\frac{0.86435678 \gamma(W / S)}{32 C_{\sigma}\left(t_{\max } / c\right) \sigma_{\max }} \frac{\kappa_{W} W_{r} W^{2}}{W_{S}}\right]^{2 / 3}
\end{gathered}
$$

Taylor and Hunsaker [16] have also shown that for linearly tapered wings, the lift distribution that minimizes induced drag is very similar to that shown in Eq. (13), regardless of the degree of taper.

For the deflection-limited design of a rectangular wing with the weight distribution specified by Eq. (5) and any all-positive spanwise-symmetric lift distribution, the total weight of the wing structure required to support the bending-moment distribution at the design limit is given by [9]

$$
W_{s}=\frac{\gamma(W / S)^{2}}{32 C_{\delta} E\left(t_{\max } / c\right)^{2} \delta_{\max }} \frac{\kappa_{W} W_{r} b^{6}}{W^{2}}\left(1+B_{3}\right) ; \quad C_{\delta} \equiv \frac{8 I\left(h / t_{\max }\right)^{2}}{A h^{2}}
$$

Under the constraints of a fixed lift distribution, fixed gross weight, fixed maximum deflection, and fixed wing loading, the induced drag is minimized using a lift distribution having

$$
B_{3}=-3 / 7+\sqrt{9 / 49-1 / 21} ; \quad B_{n}=0, \text { for } n \neq 3
$$

which yields the optimum results

$$
\begin{gathered}
\frac{b \widetilde{L}(\theta)}{L}=\frac{4}{\pi}[\sin (\theta)-0.05971587 \sin (3 \theta)] \\
b=\sqrt[6]{\frac{32 C_{\delta} E\left(t_{\max } / c\right)^{2} \delta_{\max }}{0.94028413 \gamma(W / S)^{2}} \frac{W_{S} W^{2}}{\kappa_{W} W_{r}}} \\
D_{i}=\frac{2.02139591}{\pi \rho V_{\infty}^{2}}\left[\frac{0.94028413 \gamma(W / S)^{2}}{32 C_{\delta} E\left(t_{\max } / c\right)^{2} \delta_{\max }} \frac{\kappa_{W} W_{r} W^{4}}{W_{S}}\right]^{1 / 3}
\end{gathered}
$$

Note that although deflection limits may not always be explicitly enforced in practice, some limit on deflection should at least be considered to preclude wing strike during a hard landing. Furthermore, excessive wingtip deflection during flight can adversely affect the aerodynamics and flight mechanics of an aircraft. For highly flexible aircraft, these adverse effects can be very significant [29]. Therefore, in this paper, both stress and deflection limits will be considered.

The optimum lift distributions given in Eqs. (3), (13), and (18) were all obtained under the constraint that a single lift distribution is used during all flight phases, and the same constraint is used for all subsequent results presented in this paper. However, in general, the lift distribution for a wing with fixed geometry changes depending 
on the load factor. Therefore, in order for this constraint to be satisfied, we must assume that wing twist can be varied during flight to maintain a single lift distribution at all loading conditions. This can be done using variable geometric and/or aerodynamic twist [30-35]. However, the designer is not always constrained to a single lift distribution. Variable geometric and/or aerodynamic twist can also be used to implement different lift distributions during different flight phases [4,5,7,8,30-35]. For example, the lift distribution given by Eq. (13) could be implemented during high-load-factor maneuvers; other lift distributions could be implemented during takeoff and landing; and the elliptic lift distribution could be implemented during steady level flight. This would allow an increase in the wingspan over that allowed by a fixed elliptic lift distribution, without increasing the gross weight or imposing any induced-drag penalty during steady level flight.

Although the approximations associated with lifting-line theory were used to obtain the solutions presented here, for unswept wings of aspect ratio greater than 4, lifting-line theory has been shown to be in excellent agreement with experimental data and grid-resolved CFD solutions, and lifting-line solutions are widely accepted [3-7,36-71]. Furthermore, although some important design considerations are neglected when using lifting-line theory, analytic solutions such as those presented in this paper provide insight into the relationships between design parameters and the relative influence of those parameters on the aerodynamics of a finite wing. In fact, a significant portion of our current understanding of finite-wing aerodynamics, including the relationship between lift distribution, twist distribution, chord distribution, and induced drag, comes from early analytic solutions based on lifting-line theory. Designers often rely on principles based on these solutions during conceptual design phases. Some of these solutions are also used for benchmarking numerical tools. The results presented in this paper have the same utility as these early analytic solutions. As will be shown, the results in this paper reveal important aspects about the aerodynamic and structural coupling involved in designing a wing for minimum induced drag and provide excellent examples for benchmarking higher-fidelity multidisciplinary optimization tools.

\section{Minimizing Induced Drag with Wingspan and Wing-Structure Weight}

Minimizing induced drag by varying the wingspan and lift distribution while holding gross weight constant is not the only variational problem suggested by Eq. (2). Because the wing-structure weight is proportional to the wing bending moments, the wing-structure weight increases with increasing wingspan for any fixed lift and weight distributions. Therefore, Eq. (2) also suggests that the induced drag could be minimized by varying the wingspan $b$ and allowing the wing-structure weight $W_{s}$ to change while holding the net weight $W_{n}$ and lift distribution $b \widetilde{L}(z) / L$ fixed. Because the required wing-structure weight depends on both the wingspan and the lift distribution, in general, $W_{s}$ depends on $b$ and all of the Fourier coefficients $B_{n}$. Because gross weight is simply the sum of $W_{n}$ and $W_{s}$, for an arbitrary wing design, Eq. (2) can be written 


$$
D_{i}=\frac{2}{\pi \rho V_{\infty}^{2}}\left(\frac{W_{n}}{b}+\frac{W_{s}\left(b, B_{n}\right)}{b}\right)^{2}\left(1+\sum_{n=2}^{\infty} n B_{n}^{2}\right)
$$

For any fixed $W_{n}$, the term $W_{n} / b$ always decreases with increasing wingspan; and for typical design constraints, the term $W_{s}\left(b, B_{n}\right) / b$ increases with increasing wingspan. For example, the design constraints that led to Prandtl's 1933 lift distribution yield $W_{s}$ proportional to $b^{2}$ as given in Eq. (10); the design constraints that led to the lift distribution given in Eq. (13) yield $W_{s}$ proportional to $b^{3}$ as given in Eq. (11); and the design constraints that led to the lift distribution given in Eq. (18) yield $W_{s}$ proportional to $b^{6}$ as given in Eq. (16). For any fixed lift and weight distributions, there is an optimum wingspan for minimizing the induced drag, which is based on the tradeoff between the wingspan $b$ and the wing-structure weight $W_{s}$.

For example, for the stress-limited design of a rectangular wing with the weight distribution specified by Eq. (5) and any all-positive spanwise-symmetric lift distribution, the total weight of the wing structure required to support the bending-moment distribution at the design limit is given by Eq. (11). The gross weight is the sum $W=W_{n}+W_{s}$. Hence, using Eq. (11) in Eq. (21), the induced drag can be written as

$$
D_{i}=\frac{2}{\pi \rho V_{\infty}^{2}}\left[\frac{W_{n}}{b}+\frac{\left(1+B_{3}\right) \gamma(W / S)}{32 C_{\sigma}\left(t_{\max } / c\right) \sigma_{\max }} \frac{\kappa_{W} W_{r} b^{2}}{W}\right]^{2}\left(1+\sum_{n=2}^{\infty} n B_{n}^{2}\right)
$$

For any given value of the ratio $\kappa_{W} W_{r} / W$, the function in the square brackets of Eq. (22) can be minimized with respect to $b$, based on the tradeoff between wingspan and wing-structure weight.

To minimize the ratio $\kappa_{W} W_{r} / W$ for any given wingspan, the weight distribution given by Eq. (6) can be used. Hence, using Eq. (6) in Eqs. (8) and (11) yields $\kappa_{W}=n_{m}$ and

$$
W_{s}=\frac{\left(1+B_{3}\right) \gamma(W / S)}{32 C_{\sigma}\left(t_{\max } / c\right) \sigma_{\max }} \frac{n_{m}\left(n_{g}-1\right)}{n_{m}+n_{g}} b^{3}
$$

From Eqs. (6), (8), and (22) the induced drag is

$$
D_{i}=\frac{2}{\pi \rho V_{\infty}^{2}}\left[\frac{W_{n}}{b}+\frac{\left(1+B_{3}\right) \gamma(W / S)}{32 C_{\sigma}\left(t_{\max } / c\right) \sigma_{\max }} \frac{n_{m}\left(n_{g}-1\right)}{n_{m}+n_{g}} b^{2}\right]^{2}\left(1+\sum_{n=2}^{\infty} n B_{n}^{2}\right)
$$

The wingspan that minimizes this induced drag for a fixed lift distribution and fixed wing loading is

$$
b=\sqrt[3]{\frac{16 C_{\sigma}\left(t_{\max } / c\right) \sigma_{\max } W_{n}}{\left(1+B_{3}\right) \gamma(W / S)} \frac{n_{m}+n_{g}}{n_{m}\left(n_{g}-1\right)}}
$$

Using Eq. (25) in Eq. (23), the wing-structure weight that minimizes this induced drag for any fixed value of $B_{3}$ is

$$
W_{s}=\frac{1}{2} W_{n}
$$


Using Eq. (25) in Eq. (24), the associated minimum induced drag is

$$
D_{i}=\frac{9}{2 \pi \rho V_{\infty}^{2}}\left[\frac{\left(1+B_{3}\right) \gamma(W / S) W_{n}^{2}}{16 C_{\sigma}\left(t_{\max } / c\right) \sigma_{\max }} \frac{n_{m}\left(n_{g}-1\right)}{n_{m}+n_{g}}\right]^{2 / 3}\left(1+\sum_{n=2}^{\infty} n B_{n}^{2}\right)
$$

It should be emphasized that the wing-structure weight is not an independent variable, but rather a dependent variable, related to the wingspan, lift distribution, load factor, and other independent design variables, as shown in Eq. (23). Therefore, the relation shown in Eq. (26) results from the optimum solution, and requires that the optimum net weight distribution and wingspan are used in accordance with the design constraints.

Equation (27) gives the minimum possible induced drag for the stress-limited design of a rectangular wing with fixed wing loading, the weight distribution specified by Eq. (5), and any fixed all-positive spanwise-symmetric lift distribution. However, even though Eq. (6) was used to minimize the ratio $\kappa_{W} W_{r} / W$ in Eq. (22), Eq. (27) does not provide an absolute minimum in induced drag for the specified design constraints and weight distribution, unless the optimum lift distribution is also used. From Eq. (27), we see that the variation of this drag with the Fourier coefficients $B_{n}$ is proportional to $\left(1+\sum n B_{n}^{2}\right)\left(1+B_{3}\right)^{2 / 3}$. Minimizing this function yields the Fourier coefficients given in Eq. (12) and the optimum lift distribution given in Eq. (13).

The optimum wing-structure weight given in Eq. (26) and the optimum lift distribution given in Eq. (13) are for the stress-limited design of a rectangular wing with fixed wing loading. However, Taylor and Hunsaker [16] have shown that the solution given in Eq. (26) also holds for the stress-limited design of a tapered wing with fixed wing loading. Furthermore, the reader is reminded that the optimum lift distribution that minimizes induced drag for tapered wings does not deviate significantly from that given in Eq. (13), regardless of the degree of taper [16].

For the deflection-limited design of a rectangular wing with any fixed all-positive spanwise-symmetric lift distribution and the weight distribution specified by Eqs. (5) and (6), the total weight of the wing structure required to support the bending-moment distribution at the design limit is given by Eq. (16). Hence, using Eqs. (6), (8), and (16) with the relation $W=W_{n}+W_{s}$ yields

$$
W=W_{n}+\frac{\left(1+B_{3}\right) \gamma(W / S)^{2}}{32 C_{\delta} E\left(t_{\max } / c\right)^{2} \delta_{\max }} \frac{n_{m}\left(n_{g}-1\right)}{n_{m}+n_{g}} \frac{b^{6}}{W}
$$

Equation (28) is easily solved for the gross weight, and using the relation $W_{s}=W-W_{n}$ yields

$$
W_{s}=-\frac{W_{n}}{2}+\sqrt{\frac{W_{n}^{2}}{4}+\frac{\left(1+B_{3}\right) \gamma(W / S)^{2}}{32 C_{\delta} E\left(t_{\max } / c\right)^{2} \delta_{\max }} \frac{n_{m}\left(n_{g}-1\right)}{n_{m}+n_{g}} b^{6}}
$$

Using this wing-structure weight with the relation $W=W_{n}+W_{s}$ in Eq. (2) gives 


$$
D_{i}=\frac{2}{\pi \rho V_{\infty}^{2}}\left(\frac{W_{n}}{2 b}+\sqrt{\frac{W_{n}^{2}}{4 b^{2}}+\frac{\left(1+B_{3}\right) \gamma(W / S)^{2}}{32 C_{\delta} E\left(t_{\max } / c\right)^{2} \delta_{\max }} \frac{n_{m}\left(n_{g}-1\right)}{n_{m}+n_{g}} b^{4}}\right)^{2}\left(1+\sum_{n=2}^{\infty} n B_{n}^{2}\right)
$$

The wingspan that minimizes this induced drag for any fixed $W_{n}$, fixed lift distribution, and fixed wing loading is

$$
b=\sqrt[6]{\frac{10 C_{\delta} E\left(t_{\max } / c\right)^{2} \delta_{\max } W_{n}^{2}}{\left(1+B_{3}\right) \gamma(W / S)^{2}} \frac{n_{m}+n_{g}}{n_{m}\left(n_{g}-1\right)}}
$$

Using Eq. (31) in Eq. (29), the wing-structure weight that minimizes this induced drag for any fixed value of $B_{3}$ is

$$
W_{s}=\frac{1}{4} W_{n}
$$

Using Eq. (31) in Eq. (30), the associated minimum induced drag is

$$
D_{i}=\frac{25}{8 \pi \rho V_{\infty}^{2}}\left[\frac{\left(1+B_{3}\right) \gamma(W / S)^{2} W_{n}^{4}}{10 C_{\delta} E\left(t_{\max } / c\right)^{2} \delta_{\max }} \frac{n_{m}\left(n_{g}-1\right)}{n_{m}+n_{g}}\right]^{1 / 3}\left(1+\sum_{n=2}^{\infty} n B_{n}^{2}\right)
$$

Here again, even though Eq. (6) was used to minimize $W_{s}$ for any given wingspan, Eq. (33) does not provide an absolute minimum in induced drag for the specified design constraints and weight distribution, unless the optimum lift distribution is also used. From Eq. (33), we see that the variation of this drag with the Fourier coefficients $B_{n}$ is proportional to $\left(1+\sum n B_{n}^{2}\right)\left(1+B_{3}\right)^{1 / 3}$. Minimizing this function yields the Fourier coefficients given in Eq. (17) and the optimum lift distribution given in Eq. (18).

The optimum wing-structure weights shown in Eqs. (26) and (32) are typical of those seen in many sailplanes [72]. This should not be surprising, since sailplanes are designed to operate with maximum efficiency at conditions where induced drag is a significant portion of the total drag. However, for other aircraft types, these results may not be practical due to additional constraints. Moreover, the results shown in Eqs. (23)-(27) and (29)-(33) are for a rectangular wing with the weight distribution given in Eqs. (5) and (6), which minimizes the bending moment required for any given wingspan at the constraining design limit. However, the reader is reminded that this weight distribution is not always practical due to other design constraints. Numerical methods can be used to evaluate the optimum wingspan and wing-structure weight required to minimize induced drag for other weight distributions and/or wing planforms [16].

\section{Minimum Induced Drag for Fixed Net Weight, Maximum Stress, and Stall Speed}

Minimizing induced drag for a rectangular wing with spanwise-symmetric lift and the weight distribution specified by Eq. (5) requires a lift distribution having $B_{n}=0$ for all $n \neq 3$ with $-1 / 3 \leq B_{3} \leq 0$. Using these constraints in Eq. (1) yields 


$$
\widetilde{C}_{L}(\theta)=\frac{4}{\pi} C_{L}\left[\sin (\theta)+B_{3} \sin (3 \theta)\right]
$$

For a rectangular wing with $-1 / 3 \leq B_{3} \leq 0$, the maximum section lift coefficient always occurs at the wing root, i.e., $\theta=\pi / 2$. From Eq. (34), the maximum wing lift coefficient is related to the maximum section lift coefficient by

$$
C_{L_{\max }}=\frac{\pi}{4\left[\sin (\pi / 2)+B_{3} \sin (3 \pi / 2)\right]} \widetilde{C}_{L_{\max }}=\frac{\pi}{4\left(1-B_{3}\right)} \widetilde{C}_{L_{\max }}
$$

At the stall speed, Eq. (35) requires

$$
\frac{n_{a}\left(W_{n}+W_{s}\right)}{\frac{1}{2} \rho V_{\text {stall }}^{2} S}=\frac{\pi}{4\left(1-B_{3}\right)} \widetilde{C}_{L_{\max }} \quad \text { or } \quad S=\frac{8\left(1-B_{3}\right) n_{a}\left(W_{n}+W_{s}\right)}{\pi \rho V_{\text {stall }}^{2} \widetilde{C}_{L_{\max }}}
$$

For the stress-limited design of a rectangular wing with any fixed all-positive spanwise-symmetric lift distribution and the weight distribution specified by Eq. (5), the total weight of the wing structure required to support the bending-moment distribution at the design limit is given by Eq. (11). To minimize the ratio $\kappa_{W} W_{r} / W$ for any given wingspan, the optimum weight distribution given in Eq. (6) can be used as well. Thus, using Eqs. (6) and (8) in Eq. (11) and rearranging yields

$$
W_{s}=\frac{\gamma n_{m}\left(n_{g}-1\right)\left(W_{n}+W_{s}\right)}{32 C_{\sigma}\left(t_{\max } / c\right) \sigma_{\max }\left(n_{m}+n_{g}\right)} \frac{\left(1+B_{3}\right) b^{3}}{S}
$$

At this point it is convenient to define an important characteristic length associated with this stress-limited design

$$
b_{\sigma} \equiv\left[\frac{C_{\sigma}\left(t_{\max } / c\right) \sigma_{\max } n_{a}\left(n_{m}+n_{g}\right) W_{n}}{\pi \rho V_{\text {stall }}^{2} \widetilde{C}_{L_{\max }} \gamma n_{m}\left(n_{g}-1\right)}\right]^{1 / 3}
$$

Using Eqs. (36) and (38) to eliminate the planform area from Eq. (37) yields

$$
W_{s}=\frac{\left(1+B_{3}\right) W_{n} b^{3}}{256\left(1-B_{3}\right) b_{\sigma}^{3}}
$$

Using this wing-structure weight with the relation $W=W_{n}+W_{s}$ in Eq. (2) gives

$$
D_{i}=\frac{2}{\pi \rho V_{\infty}^{2}}\left[\frac{W_{n}}{b}+\frac{\left(1+B_{3}\right) W_{n} b^{2}}{256\left(1-B_{3}\right) b_{\sigma}^{3}}\right]^{2}\left(1+\sum_{n=2}^{\infty} n B_{n}^{2}\right)
$$

The wingspan that minimizes this induced drag for any fixed lift distribution and net weight is

$$
b=\left(\frac{128\left(1-B_{3}\right)}{1+B_{3}}\right)^{1 / 3} b_{\sigma}
$$

Using Eq. (41) to eliminate $b$ from Eq. (39), the wing-structure weight that minimizes the induced drag for fixed $W_{n}$, fixed $\sigma_{\max }$, fixed $V_{\text {stall }}$, and any fixed value of $B_{3}$ is 


$$
W_{s}=\frac{1}{2} W_{n}
$$

Using Eq. (41) to eliminate $b$ from Eq. (40) with $B_{n}=0$ for all $n \neq 3$, the minimum induced drag for a fixed lift distribution, fixed $W_{n}$, fixed $\sigma_{\max }$, and fixed $V_{\text {stall }}$ can be written as

$$
D_{i}=\left(\frac{1+B_{3}}{128\left(1-B_{3}\right)}\right)^{2 / 3} \frac{9\left(1+3 B_{3}^{2}\right) W_{n}^{2}}{2 \pi \rho V_{\infty}^{2} b_{\sigma}^{2}}
$$

The variation of this drag with $B_{3}$ is proportional to $\left[\left(1+3 B_{3}^{2}\right)^{3}\left(1+B_{3}\right)^{2} /\left(1-B_{3}\right)^{2}\right]^{1 / 3}$. Thus, for fixed $W_{n}$, fixed $\sigma_{\max }$, and fixed $V_{\text {stall }}$, the value of $B_{3}$ that minimizes the induced drag predicted from Eq. (43) is obtained from

$$
9 B_{3}^{3}-6 B_{3}^{2}-9 B_{3}-2=0
$$

The roots of this cubic equation are

$$
B_{3}=\frac{1}{2}-\sqrt{\frac{11}{12}}, \quad B_{3}=-\frac{1}{3}, \quad B_{3}=\frac{1}{2}+\sqrt{\frac{11}{12}}
$$

Using the only root in the range $-1 / 3 \leq B_{3} \leq 0$, Eqs. (1), (41), (36), and (43) result in

$$
\begin{gathered}
\frac{b \widetilde{L}(\theta)}{L}=\frac{4}{\pi}\left[\sin (\theta)-\frac{1}{3} \sin (3 \theta)\right] \\
b=\sqrt[3]{256} b_{\sigma} \\
S=\frac{16 n_{a} W_{n}}{\pi \rho V_{\text {stall }}^{2} \widetilde{C}_{L_{\max }}} \\
D_{i}=\frac{6 W_{n}^{2}}{\left(256^{2 / 3}\right) \pi \rho V_{\infty}^{2} b_{\sigma}^{2}}
\end{gathered}
$$

For a fixed elliptic lift distribution, Eqs. (41), (36), and (43) result in

$$
\begin{gathered}
b=\sqrt[3]{128} b_{\sigma} \\
S=\frac{12 n_{a} W_{n}}{\pi \rho V_{\text {stall }}^{2} \widetilde{C}_{L_{\max }}} \\
D_{i}=\frac{9 W_{n}^{2}}{2\left(128^{2 / 3}\right) \pi \rho V_{\infty}^{2} b_{\sigma}^{2}}
\end{gathered}
$$

In summary, under the constraints of a fixed lift distribution, fixed net weight, fixed maximum stress, and fixed stall speed, minimizing induced drag for a rectangular wing with spanwise-symmetric lift and the optimum weight distribution specified by Eqs. (5) and (6) requires a lift distribution having $B_{n}=0$ for all $n \neq 3$ with $-1 / 3 \leq B_{3} \leq 0$. With these constraints and any fixed value of $B_{3}$, the induced drag is minimized using a wingstructure weight equal to one half the net weight as given in Eq. (42). This induced drag is further minimized by 
using the lift distribution given in Eq. (46), which is exactly Prandtl's 1933 lift distribution as given in Eq. (3). Comparing Eqs. (47)-(49) with Eqs. (50)-(52), we see that, for this wing geometry, weight distribution, and design constraints, the fixed lift distribution given in Eq. (46) results in a $25.99 \%$ increase in the wingspan, a $33.33 \%$ increase in the planform area, and a $16.01 \%$ decrease in the induced drag over those obtained for a fixed elliptic lift distribution with the same net weight, maximum stress, and stall speed.

\section{Minimum Induced Drag for Fixed Net Weight, Maximum Deflection, and Stall Speed}

For the deflection-limited design of a rectangular wing with any fixed all-positive spanwise-symmetric lift distribution and the weight distribution specified by Eq. (5), the total weight of the wing structure required to support the bending-moment distribution at the design limit is given by Eq. (16), which can be rearranged as

$$
W_{s}=\frac{\gamma \kappa_{W} W_{r}}{32 C_{\delta} E\left(t_{\max } / c\right)^{2} \delta_{\max }} \frac{\left(1+B_{3}\right) b^{6}}{S^{2}}
$$

Using Eq. (36) to eliminate the planform area from Eq. (53) and applying Eq. (6) to minimize $W_{s}$ for any given wingspan yields

$$
W_{s}=\frac{\left(1+B_{3}\right) b^{6} W_{n}^{2}}{2048\left(1-B_{3}\right)^{2} b_{\delta}^{6}\left(W_{n}+W_{s}\right)}
$$

where $b \delta$ is an important characteristic length associated with this deflection-limited design,

$$
b_{\delta} \equiv\left[\frac{C_{\delta} E\left(t_{\max } / c\right)^{2} \delta_{\max } n_{a}^{2}\left(n_{m}+n_{g}\right) W_{n}^{2}}{\left(\pi \rho V_{\text {stall }}^{2} \widetilde{C}_{L_{\max }}\right)^{2} \gamma n_{m}\left(n_{g}-1\right)}\right]^{1 / 6}
$$

Equation (54) can be rearranged as a quadratic equation in $W_{s}$ to give

$$
W_{s}^{2}+W_{n} W_{s}-\frac{\left(1+B_{3}\right) b^{6} W_{n}^{2}}{2048\left(1-B_{3}\right)^{2} b_{\delta}^{6}}=0
$$

The only positive root of Eq. (56) is given by

$$
W_{s}=-\frac{W_{n}}{2}+\frac{W_{n}}{2} \sqrt{1+\frac{\left(1+B_{3}\right) b^{6}}{512\left(1-B_{3}\right)^{2} b_{\delta}^{6}}}
$$

Using this wing-structure weight with the relation $W=W_{n}+W_{s}$ in Eq. (2) gives

$$
D_{i}=\frac{2}{\pi \rho V_{\infty}^{2}}\left[\frac{W_{n}}{2}\left(\frac{1}{b}+\sqrt{\frac{1}{b^{2}}+\frac{\left(1+B_{3}\right) b^{4}}{512\left(1-B_{3}\right)^{2} b_{\delta}^{6}}}\right)\right]^{2}\left(1+\sum_{n=2}^{\infty} n B_{n}^{2}\right)
$$

The wingspan that minimizes this induced drag for any fixed lift distribution and net weight is 


$$
b=\left[\frac{640\left(1-B_{3}\right)^{2}}{\left(1+B_{3}\right)}\right]^{1 / 6} b_{\delta}
$$

Using Eq. (59) to eliminate $b$ from Eq. (57), the wing-structure weight that minimizes the induced drag for fixed $W_{n}$, fixed $\delta_{\max }$, fixed $V_{\text {stall }}$, and any fixed value of $B_{3}$ is

$$
W_{s}=\frac{1}{4} W_{n}
$$

Using Eq. (59) to eliminate $b$ from Eq. (58) with $B_{n}=0$ for all $n \neq 3$, the minimum induced drag for a fixed lift distribution, fixed $W_{n}$, fixed $\delta_{\max }$, and fixed $V_{\text {stall }}$ can be written as

$$
D_{i}=\left(\frac{1+B_{3}}{10\left(1-B_{3}\right)^{2}}\right)^{1 / 3} \frac{25\left(1+3 B_{3}^{2}\right) W_{n}^{2}}{32 \pi \rho V_{\infty}^{2} b_{\delta}^{2}}
$$

The variation of this drag with $B_{3}$ is proportional to $\left[\left(1+3 B_{3}^{2}\right)^{3}\left(1+B_{3}\right) /\left(1-B_{3}\right)^{2}\right]^{1 / 3}$. Thus, for fixed $W_{n}$, fixed $\delta_{\max }$, and fixed $V_{\text {stall }}$, the value of $B_{3}$ that minimizes the induced drag predicted from Eq. (61) is obtained from

$$
15 B_{3}^{3}-9 B_{3}^{2}-19 B_{3}-3=0
$$

The roots of this cubic equation are

$$
B_{3}=-0.74279033, \quad B_{3}=-0.17714856, \quad B_{3}=1.5199389
$$

Using the only root in the range $-1 / 3 \leq B_{3} \leq 0$, Eqs. (1), (59), (36), and (61) result in

$$
\begin{gathered}
\frac{b \widetilde{L}(\theta)}{L}=\frac{4}{\pi}[\sin (\theta)-0.17714856 \sin (3 \theta)] \\
b=3.2019916 b_{\delta} \\
S=11.771486 \frac{n_{a} W_{n}}{\pi \rho V_{\text {stall }}^{2} \widetilde{C}_{L_{\max }}} \\
D_{i}=0.33349127 \frac{W_{n}^{2}}{\pi \rho V_{\infty}^{2} b_{\delta}^{2}}
\end{gathered}
$$

For a fixed elliptic lift distribution, Eqs. (59), (36), and (61) result in

$$
\begin{gathered}
b=\left(640^{1 / 6}\right) b_{\delta} \\
S=\frac{10 n_{a} W_{n}}{\pi \rho V_{\text {stall }}^{2} \widetilde{C}_{L_{\max }}} \\
D_{i}=\frac{25 W_{n}^{2}}{32\left(10^{1 / 3}\right) \pi \rho V_{\infty}^{2} b_{\delta}^{2}}
\end{gathered}
$$


In summary, under the constraints of a fixed lift distribution, fixed net weight, fixed maximum deflection, and fixed stall speed, minimizing induced drag for a rectangular wing with spanwise-symmetric lift and the optimum weight distribution specified by Eqs. (5) and (6) requires a lift distribution having $B_{n}=0$ for all $n \neq 3$ and $-1 / 3 \leq B_{3} \leq 0$. With these constraints and any fixed value of $B_{3}$, induced drag is minimized using a wing-structure weight equal to one fourth the net weight as given in Eq. (60). This induced drag is further minimized by using the lift distribution given in Eq. (64). Comparing Eqs. (65)-(67) with Eqs. (68)-(70), we see that, for this wing geometry, weight distribution, and design constraints, the fixed lift distribution given in Eq. (64) results in a 9.07\% increase in the wingspan, a $17.71 \%$ increase in the planform area, and an $8.03 \%$ decrease in the induced drag over those obtained for a fixed elliptic lift distribution with the same net weight, maximum deflection, and stall speed.

It should be noted that for both the stress-limited design and the deflection-limited design of a rectangular wing with fixed stall speed, the optimum solution requires an increase in planform area over a wing designed with a fixed elliptic lift distribution. Because the viscous drag is related to the planform area, the designs that minimize induced drag may not be the designs that minimize total drag. The same is true for the case of fixed wing loading, where a change in wing-structure weight requires a corresponding change in the wing area. Moreover, in order to obtain the optimum lift distributions given in Eqs. (13), (18), (46) and (64) on a rectangular planform, the wing must be twisted. As shown by Stewart and Hunsaker [73], the viscous drag introduced by this twist can reduce the benefits of using the minimum-induced-drag solution. Therefore, when designing a wing for minimum total drag, viscous effects should be considered. Although viscous effects are not considered in this study, the optimum solutions presented here provide valuable insight into the coupling between lift distribution, wingspan, and wing-structure weight and their effect on induced drag.

\section{Results}

The optimum wingspans given in Eqs. (25), (31), (41), and (59) all minimize induced drag for a rectangular wing with fixed net weight and any fixed all-positive spanwise-symmetric lift distribution combined with other design constraints. Equation (25) is for a stress-limited design with fixed wing loading; Eq. (31) is for a deflectionlimited design with fixed wing loading; Eq. (41) is for a stress-limited design with fixed stall speed; and Eq. (59) is for a deflection-limited design with fixed stall speed. The optimum wing-structure weights corresponding to the optimum wingspans given in Eqs. (25), (31), (41), and (59) are respectively given in Eqs. (26), (32), (42), and (60). Although induced drag depends on all of the Fourier coefficients $B_{n}$ in Eq. (1), for an arbitrary lift distribution, the optimum wingspans computed from Eqs. (25), (31), (41), and (59) depend only on the single Fourier coefficient $B_{3}$.

Although the wingspans from Eqs. (25), (31), (41), and (59) give the minimum possible induced drag for the specified design constraints and any fixed all-positive spanwise-symmetric lift distribution, these optimum wingspans do not provide an absolute minimum in induced drag for the specified design constraints unless the optimum lift 
distribution is also used. The optimum lift distributions corresponding to the optimum wingspans given in Eqs. (25), (31), (41), and (59) are respectively given in Eqs. (13), (18), (46), and (64). Figure 1 shows each of these four lift distributions compared with the elliptic lift distribution and the lift distribution produced by an untwisted rectangular wing. The distribution labeled (a) is the elliptic lift distribution, and that labeled (b) is Prandtl's 1933 lift distribution, which is also the lift distribution given in Eq. (46) that minimizes induced drag for a stress-limited design with fixed stall speed. The lift distribution labeled (c) is that produced by an untwisted rectangular wing of aspect ratio 8. Lift distribution (d) is that from Eq. (13), which minimizes induced drag for a stress-limited design with fixed wing loading, (e) is the lift distribution from Eq. (18) that minimizes induced drag for a deflection-limited design with fixed wing loading, and (f) is the lift distribution from Eq. (64) that minimizes induced drag for a deflection-limited design with fixed stall speed.

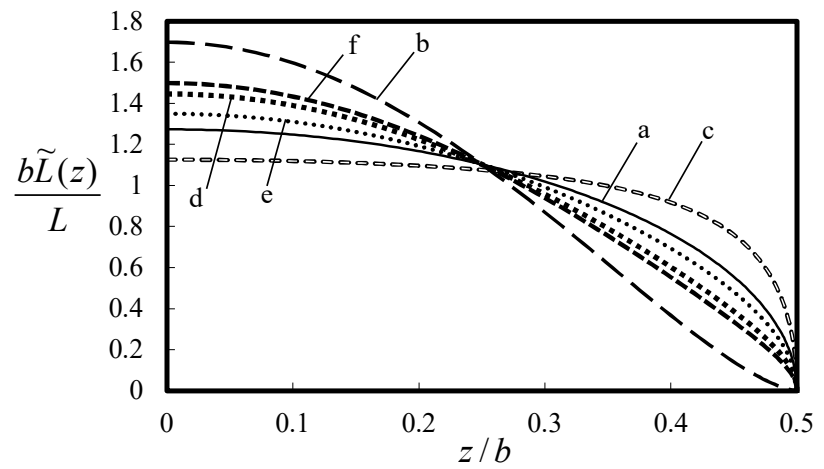

Fig. 1 Lift distributions from Eqs. (13), (18), (46), and (64) compared with the elliptic distribution and that for an untwisted rectangular wing of aspect ratio 8.

For any given lift distribution, the wingspan that minimizes induced drag depends on $B_{3}$ and the design constraints. For each of the design constraints considered in this paper, the nature of this dependence can be seen in Fig. 2, which shows the ratio of the optimum wingspan for any given value of $B_{3}$ in the range $-1 / 3 \leq B_{3} \leq 0$ to the optimum wingspan for the fixed elliptic lift distribution with the same set of design constraints. The wingspan ratios corresponding to the optimum lift distributions (a), (b), (d), (e), and (f) from Fig. 1 are labeled in Fig. 2 for reference. 


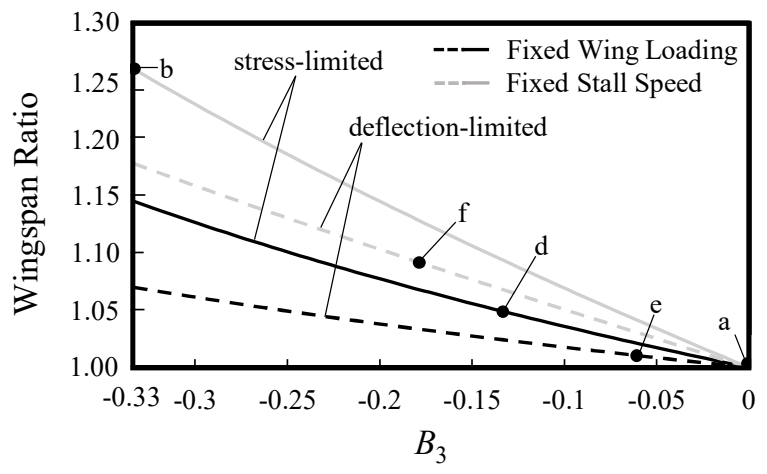

Fig. 2 Ratio of the optimum wingspan, as a function of $B_{3}$, to the optimum wingspan for the fixed elliptic lift distribution for the stress- and deflection-limited design of a wing with fixed wing loading or fixed stall speed.

For any acceptable design, both the stress and deflection constraints must be satisfied. For the stress-limited design with fixed wing loading, combining Eqs. (23) and (2) yields the following relations for the wingspan and induced drag expressed as a function of the wing-structure weight

$$
\begin{gathered}
b=\left[\frac{32 C_{\sigma}\left(t_{\max } / c\right) \sigma_{\max }}{\left(1+B_{3}\right) \gamma(W / S)} \frac{n_{m}+n_{g}}{n_{m}\left(n_{g}-1\right)} W_{s}\right]^{1 / 3} \\
D_{i}=\frac{2}{\pi \rho V_{\infty}^{2}}\left[\frac{\left(1+B_{3}\right) \gamma(W / S)}{32 C_{\sigma}\left(t_{\max } / c\right) \sigma_{\max }} \frac{n_{m}\left(n_{g}-1\right)}{n_{m}+n_{g}} \frac{\left(W_{n}+W_{s}\right)^{3}}{W_{s}}\right]^{2 / 3}\left(1+\sum_{n=2}^{\infty} n B_{n}^{2}\right)
\end{gathered}
$$

Similarly, for the deflection-limited design with fixed wing loading, combining Eqs. (29) and (2) results in

$$
\begin{gathered}
b=\left[\frac{32 C_{\delta} E\left(t_{\max } / c\right)^{2} \delta_{\max }}{\left(1+B_{3}\right) \gamma(W / S)^{2}} \frac{n_{m}+n_{g}}{n_{m}\left(n_{g}-1\right)} W_{s}\left(W_{n}+W_{s}\right)\right]^{1 / 6} \\
D_{i}=\frac{2}{\pi \rho V_{\infty}^{2}}\left[\frac{\left(1+B_{3}\right) \gamma(W / S)^{2}}{32 C_{\delta} E\left(t_{\max } / c\right)^{2} \delta_{\max }} \frac{n_{m}\left(n_{g}-1\right)}{n_{m}+n_{g}} \frac{\left(W_{n}+W_{s}\right)^{5}}{W_{s}}\right]^{1 / 3}\left(1+\sum_{n=2}^{\infty} n B_{n}^{2}\right)
\end{gathered}
$$

For the stress-limited design with fixed stall speed, combining Eqs. (39) and (2) yields

$$
\begin{gathered}
b=\left[\frac{256\left(1-B_{3}\right) W_{s}}{\left(1+B_{3}\right) W_{n}}\right]^{1 / 3} b_{\sigma} \\
D_{i}=\frac{2}{\pi \rho V_{\infty}^{2}}\left[\frac{\left(1+B_{3}\right) W_{n}\left(W_{n}+W_{s}\right)^{3}}{256\left(1-B_{3}\right) W_{s} b_{\sigma}^{3}}\right]^{2 / 3}\left(1+\sum_{n=2}^{\infty} n B_{n}^{2}\right)
\end{gathered}
$$

and for the deflection-limited design with fixed stall speed, combining Eqs. (57) and (2) gives

$$
\begin{gathered}
b=\left[\frac{2048\left(1-B_{3}\right)^{2} W_{s}\left(W_{n}+W_{s}\right)}{\left(1+B_{3}\right) W_{n}^{2}}\right]^{1 / 6} b_{\delta} \\
D_{i}=\frac{2}{\pi \rho V_{\infty}^{2}}\left[\frac{\left(1+B_{3}\right) W_{n}^{2}\left(W_{n}+W_{s}\right)^{5}}{2048\left(1-B_{3}\right)^{2} W_{s} b_{\delta}^{6}}\right]^{1 / 3}\left(1+\sum_{n=2}^{\infty} n B_{n}^{2}\right)
\end{gathered}
$$


The allowable wingspans obtained from Eqs. (71), (73), (75), and (77) always increase with increasing wingstructure weight. However, the increase in wing-structure weight with respect to wingspan is greater for the deflection-limited solutions than for the stress-limited solutions. If the wingspan is low enough, the wing-structure weight required for the deflection-limited design is less than the wing-structure weight required for the stress-limited design, and the wing design will be stress limited. On the other hand, if the wingspan is high enough, the wingstructure weight required for the stress-limited design will be less than that required for the deflection-limited design, and the wing design will be deflection limited. For the case of fixed wing loading, combining Eqs. (71) and (73), the wing-structure weight that results when the wingspan is the same for both the stress-limited and deflection-limited designs is obtained from the relation

$$
W_{s}=W_{n} /\left[\frac{32\left(C_{\sigma} \sigma_{\max }\right)^{2}\left(n_{m}+n_{g}\right)}{\left(1+B_{3}\right) C_{\delta} E \delta_{\max } \gamma n_{m}\left(n_{g}-1\right)}-1\right]
$$

Similarly, for the case of fixed stall speed, combining Eqs. (75) and (77), the wing-structure weight that results when the wingspan for both the stress-limited and deflection-limited designs is the same is obtained from

$$
W_{s}=W_{n} /\left[\frac{32 b_{\sigma}^{6}}{\left(1+B_{3}\right) b_{\delta}^{6}}-1\right]
$$

and after applying the definitions of $b_{\sigma}$ and $b_{\delta}$ from Eqs. (38) and (55), we obtain

$$
W_{s}=W_{n} /\left[\frac{32\left(C_{\sigma} \sigma_{\max }\right)^{2}\left(n_{m}+n_{g}\right)}{\left(1+B_{3}\right) C_{\delta} E \delta_{\max } \gamma n_{m}\left(n_{g}-1\right)}-1\right]
$$

which is identical to Eq. (79) obtained for fixed wing loading. Because all acceptable designs must satisfy both the stress-limited and deflection-limited constraints, the wing-structure weight given by Eq. (79) is an important parameter in this design space. Optimal designs resulting in a wing-structure weight less than that given by Eq. (79) will be stress limited and those resulting in a greater wing-structure weight will be deflection limited.

As an example of minimizing induced drag with fixed net weight and wing loading, consider an airplane with a rectangular wing. The net weight is fixed at $W_{n}=2600 \mathrm{lbf}$ and the wing loading is fixed at $W / S=15 \mathrm{lbf} / \mathrm{ft}^{2}$. To minimize the critical wing bending moment distribution, the weight distributions given by Eqs. (5) and (6) are used. The typical maneuvering-flight load limit for a civil aircraft is $2.5 \mathrm{~g}$. However, it is common to include a safety factor of 1.5 for the load limit. Therefore, in this example, we will use $n_{m}=n_{g}=3.75$. Additional parameters for this design are $C_{\sigma}=0.165, \quad C_{\delta}=0.653, \quad t_{\max } / c=0.12, \quad \sigma_{\max }=15.0 \times 10^{3} \mathrm{psi}, \quad \delta_{\max }=4.5 \mathrm{ft}, \quad \gamma=0.10 \mathrm{lbf} / \mathrm{in}^{3}$, $E=10.0 \times 10^{6} \mathrm{psi}, V_{\infty}=200 \mathrm{ft} / \mathrm{s}$, and $\rho=0.0023769 \mathrm{slug} / \mathrm{ft}^{3}$. 
From this example, solutions for the wingspan and induced drag obtained from Eqs. (71)-(74) are shown in Fig. 3 , plotted as a function of wing-structure weight for several different lift distributions. The lift distributions used to generate this figure are five of those shown in Fig. 1. The solution labels, a-e, used in Fig. 3 correspond to the liftdistribution labels used in Fig. 1. The solid curves in Fig. 3 correspond to the stress-limited solutions and the dashed curves are for the deflection-limited solutions. The black portion of each curve in Fig. 3 indicates the region where that solution provides the constraining limit. Each curve is shaded gray in the region where that solution does not provide the constraining limit. The solid vertical line shows the wing-structure weight $W_{s}=W_{n} / 2$, which corresponds to the minimum induced drag for the stress-limited solutions as given in Eq. (26). The dashed vertical line marks the wing-structure weight $W_{s}=W_{n} / 4$, which gives minimum induced drag for the deflection-limited solutions as given in Eq. (32).

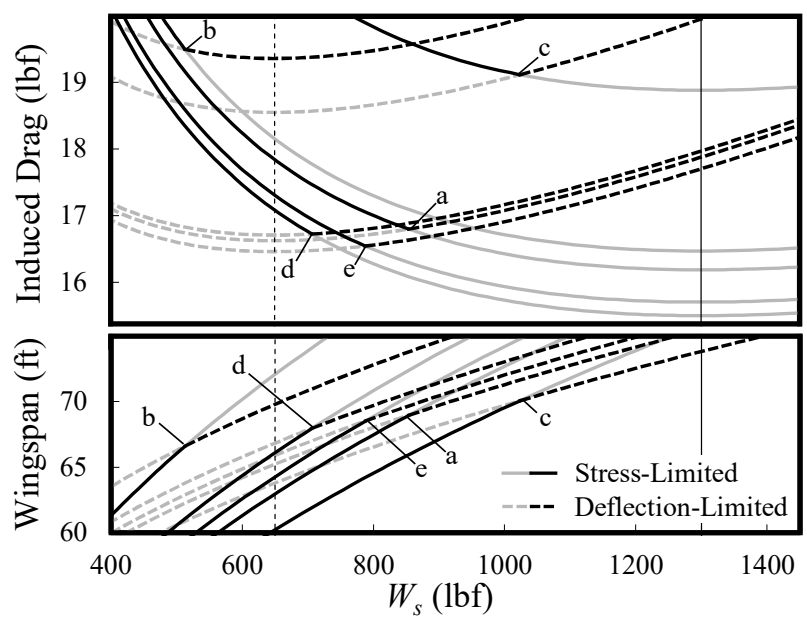

Fig. 3 Wingspan and induced-drag solutions for the fixed-wing-loading example.

Figure 3 illustrates the tradeoff between the stress-limited design and the deflection-limited design for this example. Notice from Fig. 3 that Prandtl's 1933 lift distribution (b) performs worse than the elliptic lift distribution (a), the lift distribution (c) produced by an untwisted rectangular wing, and the lift distributions (d) and (e), despite allowing the highest wingspan of the five lift distributions for any given wing-structure weight. This is, in part, because when Prandtl's 1933 lift distribution is used in conjunction with the wing parameters of this example, the design becomes deflection-limited at a lower wing-structure weight than any of the other four lift distributions. Prandtl's 1933 lift distribution gives minimum induced drag at $W_{s}=W_{n} / 4$, which is the minimum-drag point on the deflection-limited curve. For this example, even an untwisted rectangular wing (c) has a lower minimum-drag point than that produced by Prandtl's 1933 lift distribution. However, the minimum-drag point for this lift distribution is not found at the minimum-drag point for either the stress-limited or deflection-limited curve. This lift distribution yields minimum induced drag at the wing-structure weight given by Eq. (79), which is the point where the stress- 
limited curve crosses the deflection-limited curve. In fact, all lift distributions used to generate Fig. 3, except Prandtl's 1933 lift distribution, have minimum-drag points at the wing-structure weight given by Eq. (79). If the wing-structure weight computed from Eq. (79) is less than or equal to $W_{s}=W_{n} / 4$, then minimum induced drag is always obtained at $W_{s}=W_{n} / 4$. If the wing-structure weight computed from Eq. (79) is greater than $W_{s}=W_{n} / 4$ and less than $W_{s}=W_{n} / 2$, then minimum induced drag is always obtained at the wing-structure weight computed from Eq. (79). If the wing-structure weight computed from Eq. (79) is greater than or equal to $W_{s}=W_{n} / 2$, then minimum induced drag is always obtained at $W_{s}=W_{n} / 2$.

Notice that the lowest minimum-drag point shown in Fig. 3 is for the lift distribution (e) given in Eq. (18), which minimizes induced drag for the deflection-limited solution. However, the lift distribution given in Eq. (18) does not provide an absolute minimum in the induced drag for this example, because this minimum-drag point occurs at the wing-structure weight given by Eq. (79). Using the wing-structure weight from Eq. (79) in either Eq. (72) or (74), together with the other parameters specified for this example, allows us to obtain the induced drag with $B_{n}=0$ for all $n \neq 3$ as a function of the single design parameter $B_{3}$. The minimum in this function gives us the lift distribution and wing-structure weight that yield the absolute minimum induced drag for this example, i.e., $D_{i}=16.53413 \mathrm{lbf}$ at $B_{3}=-0.07245516$ and $W_{s}=774.1117 \mathrm{lbf}$. The wingspan for this optimal solution is $b=68.43317 \mathrm{ft}$. For this example, this corresponds to an induced drag coefficient of $C_{D_{i}}=0.001546$ at a lift coefficient of $C_{L}=0.3155$ and an aspect ratio of $R_{A}=20.82$. Constant induced-drag contours for the design space near this optimal solution are shown in Fig. 4. It should be emphasized that the results shown in Figs. 3 and 4 are only valid for one example aircraft configuration. Different results may be obtained by changing any of the design parameters $C_{\sigma}, C_{\delta}, t_{\max } / c, \sigma_{\max }, \delta_{\max }, \gamma$, or $E$, or by changing the design constraints. 


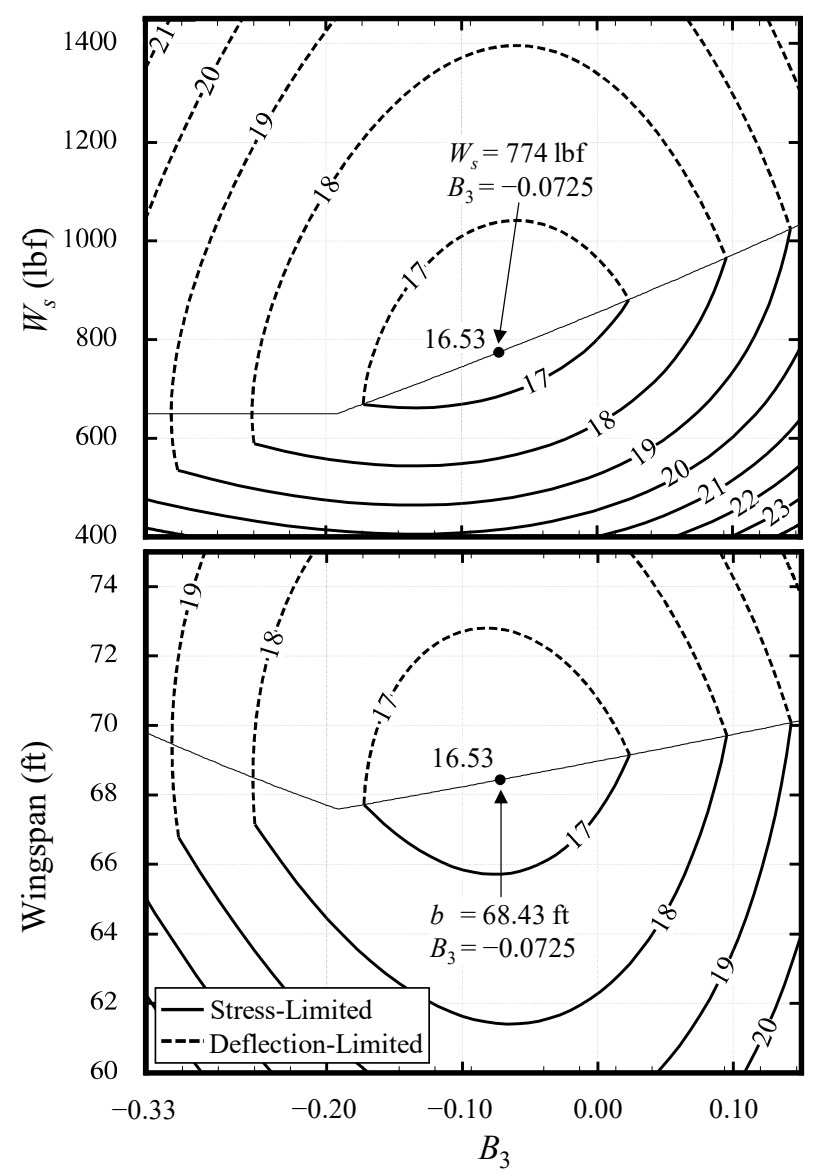

Fig. 4 Constant induced-drag contours for the fixed-wing-loading example.

As an example of minimizing induced drag with fixed net weight and stall speed, consider an airplane with a rectangular wing. The net weight is fixed at $W_{n}=2600 \mathrm{lbf}$ and the stall speed is fixed at $V_{\text {stall }}=110 \mathrm{ft} / \mathrm{s}$. Again we shall use the weight distributions given by Eqs. (5) and (6) and the values $n_{m}=n_{g}=3.75, C_{\sigma}=0.165, C_{\delta}=0.653$, $t_{\max } / c=0.12, \quad \sigma_{\max }=15.0 \times 10^{3} \mathrm{psi}, \quad \delta_{\max }=4.5 \mathrm{ft}, \quad \gamma=0.10 \mathrm{lbf} / \mathrm{in}^{3}, \quad E=10.0 \times 10^{6} \mathrm{psi}, \quad V_{\infty}=200 \mathrm{ft} / \mathrm{s}, \quad$ and $\rho=0.0023769 \mathrm{slug} / \mathrm{ft}^{3}$.

Solutions for the wingspan and induced drag obtained from Eqs. (75)-(78) are shown in Fig. 5. The lift distributions used to generate this figure are four of those shown in Fig. 1. The labels, a-c and f, correspond to the lift-distribution labels used in Fig. 1. The solid curves correspond to the stress-limited solutions and the dashed curves are for the deflection-limited solutions. The black portion of each curve indicates the region where that solution provides the constraining limit. Each curve is shaded gray in the region where that solution does not provide the constraining limit. The solid vertical line is the wing-structure weight $W_{s}=W_{n} / 2$, which gives minimum induced drag for the stress-limited solutions as given in Eq. (42). The dashed vertical line is the wing-structure weight $W_{s}=W_{n} / 4$, which gives minimum induced drag for the deflection-limited solutions as given in Eq. (60). 


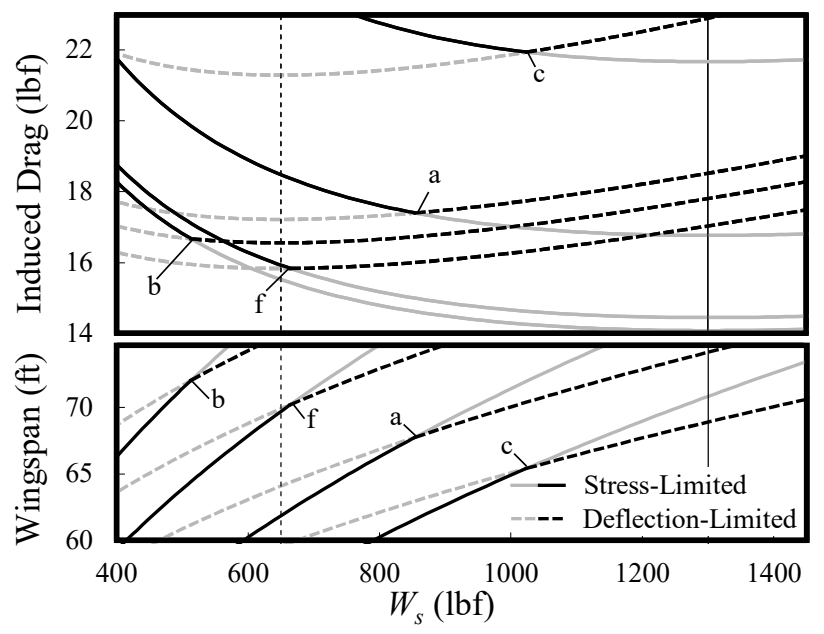

Fig. 5 Wingspan and induced-drag solutions for the fixed-stall-speed example.

From Fig. 5 we see that for Prandtl's 1933 lift distribution (b), minimum induced drag is obtained at the minimum-drag point on the deflection-limited curve. All other lift distributions used in Fig. 5 have minimum-drag points at the wing-structure weight given by Eq. (79), which is the point where the stress-limited curve crosses the deflection-limited curve. The lowest minimum-drag point shown in Fig. 5 is for the lift distribution (f) given in Eq. (64), which minimizes induced drag for the deflection-limited solution. However, the lift distribution given in Eq. (64) does not provide an absolute minimum in the induced drag for this example, because this minimum-drag point occurs at the wing-structure weight given by Eq. (79). Using the wing-structure weight from Eq. (79) in either Eq. (76) or (78), together with the other parameters specified for this example, we obtain the induced drag with $B_{n}=0$ for all $n \neq 3$ as a function of the single design parameter $B_{3}$. The minimum in this function gives the lift distribution and wing-structure weight that yield the absolute minimum induced drag for this example, i.e., $D_{i}=15.83315 \mathrm{lbf}$ at $B_{3}=-0.17889675$ and $W_{s}=662.6372 \mathrm{lbf}$. The wingspan for this optimal solution is $b=70.24208 \mathrm{ft}$. For this example, the optimal solution has an induced drag coefficient of $C_{D_{i}}=0.001369$ at a lift coefficient of $C_{L}=0.2821$ and an aspect ratio of $R_{A}=20.28$. Constant induced-drag contours for the design space near this optimal solution are shown in Fig. 6. Note from Figs. 4 and 6 that for the range of $B_{3}$ values shown here, the optimum wingspan is either deflection-limited or follows Eq. (79). In this way, the deflection limit discourages designs with excessive wingspans and excessive wingtip deflection. 


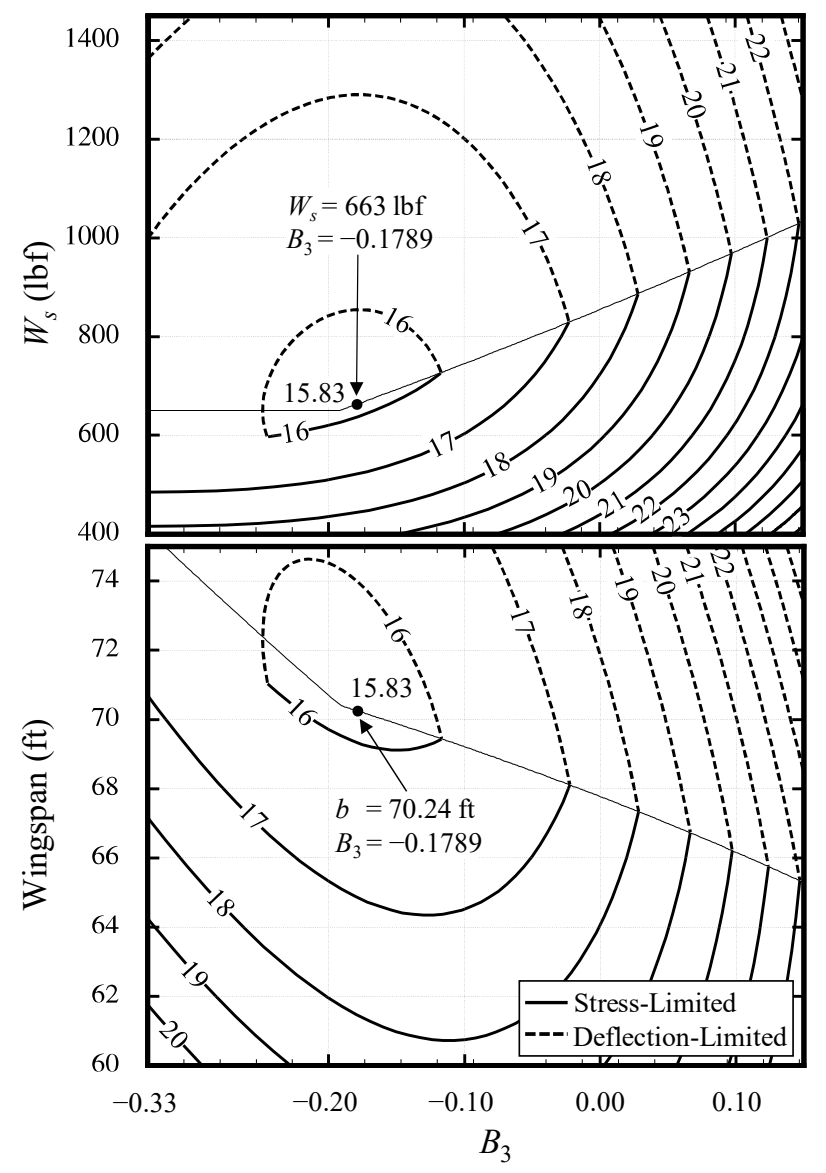

Fig. 6 Constant induced-drag contours for the fixed-stall-speed example.

It should be emphasized that the optimum solutions shown in Fig. 4 for the fixed-wing-loading example and in Fig. 6 for the fixed-stall-speed example are only valid for rectangular wings with the optimum net-weight distribution given by Eqs. (5) and (6). Figure 7 shows the net-weight distribution from Eq. (5) as a function of the normalized spanwise coordinate for each of the example optimum solutions. In order to understand whether the optimum root weight and net-weight distribution are reasonable, it is helpful to compare them to those of an airframe that may have been optimized under similar constraints. A schematic of the spanwise fuel tank and engine layout in a Boeing 777 wing $[74,75]$ is included in Fig. 7. Note that for this wing, the engine is located near the juncture of the inboard and outboard fuel tanks. For a transport aircraft such as the 777 , fuel is first burned from the inboard tanks. Once the fuel in the inboard tanks is depleted, the fuel in the outboard tanks is used [76]. Due to wing dihedral, the fuel in the outboard tanks burns from the outboard regions first. Thus, as fuel is burned, the weight distribution tends to peak near the engine location. As shown in Fig. 7, the optimum weight distributions given by Eq. (5) for the example optimum solutions given in Figs. 4 and 6 reasonably reflect this trend. At maximum takeoff weight, the Boeing 777 has a ratio of root weight to gross weight of about 0.44 [75]. For sailplanes, this ratio typically ranges between about 
0.35 and 0.72 [72]. In the two examples shown above, $n_{m}=n_{g}=3.75$. Applying this to Eq. (6) results in an optimum ratio of root weight to gross weight of 0.37 .

The reader is reminded that although the optimal net-weight distribution minimizes the wing bending moments, it may not always be practical due to additional design constraints. Nevertheless, the solutions presented in this paper are valuable for understanding the aerodynamic and structural coupling involved in designing a wing for minimum induced drag, and the reader is reminded that results for tapered planforms do not deviate significantly from many of the solutions shown here [16].

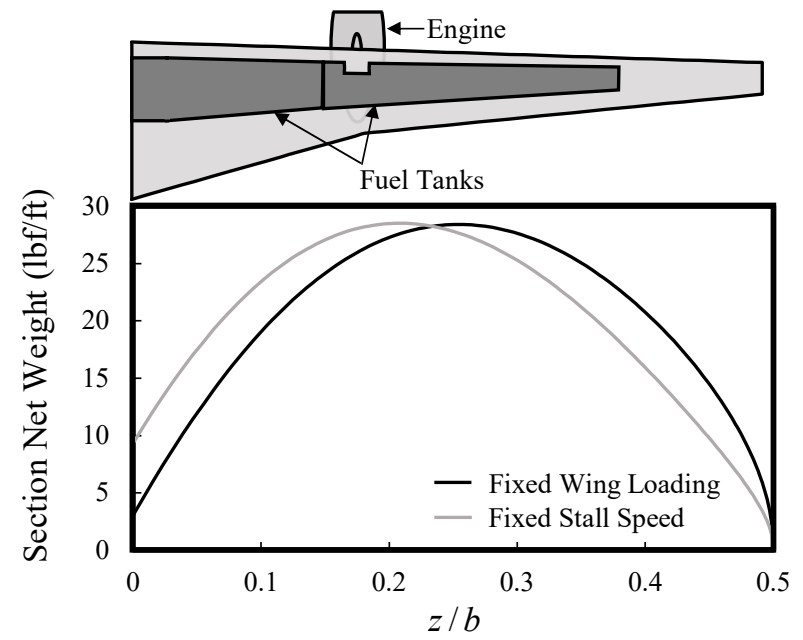

Fig. 7 Net-weight distributions corresponding to the optimum solutions for the fixed-wing-loading and fixedstall-speed examples.

\section{Conclusions}

As shown in Eq. (2), Prandtl's classical lifting-line theory predicts that the induced drag acting on the wing of an airplane in steady level flight is directly proportional to the square of the ratio of gross weight to wingspan. For any fixed weight distribution and lift distribution, the critical wing section bending moments increase with increasing wingspan and the wing-structure weight required to support these bending moments also increases with wingspan. Hence, there exists an optimum wingspan and wing-structure weight that minimizes the induced drag in steady level flight for any fixed net weight, weight distribution, and lift distribution. However, this optimum wingspan and wing-structure weight do not provide an absolute minimum in induced drag unless the optimum weight distribution and lift distribution are also used. The optimum weight distribution is obtained by enforcing both Eqs. (5) and (6). The optimum lift distribution depends on both the wing planform and the weight distribution. For the special case of a rectangular wing with spanwise-symmetric lift and the weight distribution specified by Eq. (5), the optimum lift distribution is given by Eq. (34) with $-1 / 3 \leq B_{3} \leq 0$. The precise value of $B_{3}$ that provides the absolute minimum in induced drag depends on the design constraints. 
For any wing planform and wing structural design the wing-structure weight can be determined as a function of the wingspan, maximum allowable stress, maximum allowable deflection, and other design constraints. Because gross weight is the sum of the net weight and the wing-structure weight, for any wing design, the ratio of gross weight to wingspan can be written as $W / b=W_{n} / b+W_{s} / b$. For any fixed net weight, the term $W_{n} / b$ always decreases with increasing wingspan; and for typical design constraints, the term $W_{s} / b$ increases with increasing wingspan. Thus, for typical design constraints, there is an optimum wingspan that minimizes the ratio of gross weight to wingspan based on the tradeoff between wingspan and wing-structure weight. Example analytic solutions that demonstrate this tradeoff are presented in the previous sections. It is shown that under certain constraints, induceddrag reductions in excess of $16 \%$ relative to a fixed elliptic lift distribution are possible.

Optimum solutions for two example wing designs are presented in the Results section. Figures 4 and 6 show how the induced drag varies with lift distribution, wingspan, and wing-structure weight near the optimum solution for each example. In each case, the optimum design produces a decrease in induced drag relative to the case of a fixed elliptic lift distribution.

For the analytic examples presented here, we have considered only rectangular wings with the optimum weight distribution specified by Eq. (5). This provided the great simplification of allowing us to carry out the integration in Eq. (9) for the arbitrary lift distribution given in Eq. (1) to produce the analytic results for the wing-structure weights given in Eqs. (11) and (16). When the airfoil chord length and thickness vary with the spanwise coordinate, we can no longer use Eqs. (11) and (16) to compute the wing-structure weights for the stress-limited and deflection-limited solutions. Instead, we must return to the more general relation given in Eq. (9). For arbitrary wing planforms and weight distributions, Eq. (9) could be integrated numerically. Hence, for many practical applications, numerical methods may be required to obtain optimum lift distributions, wingspans, and wing-structure weights that minimize induced drag. Nevertheless, the analytic solutions presented in this work provide significant insight into the aerodynamic and structural coupling associated with designing wings for minimum induced drag. 


\section{Acknowledgments}

This work was partially funded by the U.S. Office of Naval Research Sea-Based Aviation program, Grant No. N00014-18-1-2502, with Brian Holm-Hansen as the program officer. This work was also partially supported by the National Aeronautics and Space Administration under Grant No. 80NSSC18K1696 issued through the Aeronautics Research Mission Directorate through the 2018 NASA Fellowship Activity with Nhan Nguyen as the NASA Technical Advisor.

\section{References}

[1] Prandtl, L., "Tragflügel Theorie," Nachricten von der Gesellschaft der Wissenschaften zu Güttingen, Ges-chäeftliche Mitteilungen, Klasse, 1918, pp. 451-477.

[2] Prandtl, L., “Applications of Modern Hydrodynamics to Aeronautics,” NACA TR-116, June 1921.

[3] Phillips, W. F., "Lifting-Line Analysis for Twisted Wings and Washout-Optimized Wings," Journal of Aircraft, Vol. 41, No. 1, 2004, pp. 128-136.(doi:10.2514/1.262)

[4] Phillips, W. F., Alley, N. R., and Goodrich, W. D., "Lifting-Line Analysis of Roll Control and Variable Twist," Journal of Aircraft, Vol. 41, No. 5, 2004, pp. 1169-1176.(doi:10.2514/1.3846)

[5] Phillips, W. F., "New Twist on an Old Wing Theory," Aerospace America, January, 2005, pp. 27-30.

[6] Phillips, W. F., Fugal, S. R., and Spall, R. E., "Minimizing Induced Drag with Wing Twist, Computational-Fluid-Dynamics Validation,” Journal of Aircraft, Vol. 43, No. 2, 2006, pp. 437-444.(doi:10.2514/1.15089)

[7] Phillips, W. F., and Alley, N. R., "Predicting Maximum Lift Coefficient for Twisted Wings Using Lifting-Line Theory," Journal of Aircraft, Vol. 44, No. 3, 2007, pp. 898-910.(doi:10.2514/1.25640)

[8] Phillips, W. F., "Incompressible Flow over Finite Wings," Mechanics of Flight, 2 ${ }^{\text {nd }}$ ed., Wiley, Hoboken, NJ, 2010, pp.46-94.

[9] Phillips, W. F., Hunsaker, D. F., and Joo, J. J., "Minimizing Induced Drag with Lift Distribution and Wingspan," Journal of Aircraft, To Be Published, Preprint Available.(doi: 10.2514/1.C035027)

[10] Prandtl, L., “Über Tragflügel kleinsten induzierten Widerstandes,” Zeitschrift für Flugtechnik und Motorluftschiffahrt, Vol. 24, No. 11, 1933, pp. 305-306.

[11] Hunsaker, D. F., and Phillips, W. F., "Ludwig Prandtl's 1933 Paper Concerning wings for Minimum Induced Drag, Translation and Commentary,” AIAA SciTech 2020 Forum, Orlando, Florida, 6-10 January 2020.

[12] Jones, R. T., “The Spanwise Distribution of Lift for Minimum Induced Drag of Wings Having a Given Lift and a Given Bending Moment,” NACA TR-2249, December 1950.

[13] Jones, R. T., and Lasinski, T. A., "Effect of Winglets on the Induced Drag of Ideal Wing Shapes," NASA TM-81230, September 1980 .

[14] Klein, A., and Viswanathan, S. P., "Minimum Induced Drag of Wings with Given Lift and Root-Bending Moment," Zeitschrift fur Angewandte Mathematik und Physik, Vol. 24, 1973, pp. 886-892. 
[15] Klein, A., and Viswanathan, S. P., "Approximate Solution for Minimum Induced Drag of Wings with Given Structural Weight," Journal of Aircraft, Vol. 12, No. 2, 1975, pp. 124-126.(doi:10.2514/3.44425)

[16] Taylor, J. D., and Hunsaker D. F., "Minimum Induced Drag for Tapered Wings Including Structural Constraints,” AIAA2020-2113, AIAA Scitech 2020 Forum, Orlando, Florida, 6-10 January, 2020.(doi:10.2514/6.2020-2113)

[17] Lundry, J. L., "Minimum Swept-Wing Induced Drag with Constraints on Lift and Pitching Moment," Journal of Aircraft, Vol. 4, 1967,pp. 73-74.(doi:10.2514/3.43797)

[18] Lissaman, P. B. S., and Lundry, J. L., "A Numerical Solution for the Minimum Induced Drag of Nonplanar Wings," Journal of Aircraft, Vol. 5, 1968, pp. 17-21.(doi:10.2514/3.43901)

[19] Ashenberg, J., and Weihsradius, D., "Minimum Induced Drag of Wings with Curved Planform," Journal of Aircraft, Vol. 21, 1984, pp. 89-91.(doi:10.2514/3.56733)

[20] McGeer, T., "Wing Design for Minimum Drag with Practical Constraints," Journal of Aircraft, Vol. 21, 1984, pp. 879886.(doi:10.2514/3.45058)

[21] Rokhsaz, K., "Effect of Viscous Drag on Optimum Spanwise Lift Distribution," Journal of Aircraft, Vol. 30, 1993, pp. 152-154.(doi:10.2514/3.46328)

[22] Demasi, L., "Induced Drag Minimization: A Variational Approach Using the Acceleration Potential," Journal of Aircraft, Vol. 43, 2006, pp. 669-680.(doi:10.2514/1.15982)

[23] Demasi, L., "Erratum on Induced Drag Minimization: A Variational Approach Using the Acceleration Potential," Journal of Aircraft, Vol. 43, 2006, p. 1247.(doi:10.2514/1.26648)

[24] Demasi, L., "Investigation on the Conditions of Minimum Induced Drag of Closed Wing Systems and C-Wings," Journal of Aircraft, Vol. 44, 2007, pp. 81-99.(doi:10.2514/1.21884)

[25] Pate, D. J., and German, B. J., "Lift Distributions for Minimum Induced Drag with Generalized Bending Moment Constraints," Journal of Aircraft, Vol. 50, 2013, pp. 936-946.(doi:10.2514/1.C032074)

[26] Demasi, L., Dipace, A., Monegato, G., and Cavallaro, R., "Invariant Formulation for the Minimum Induced Drag Conditions of Nonplanar Wing Systems," AIAA Journal, Vol. 52, 2014, pp. 2223-2240.(doi:10.2514/1.J052837)

[27] Wroblewski , G. E., and Ansell, P. J., "Prediction and Experimental Evaluation of Planar Wing Spanloads for Minimum Drag," Journal of Aircraft, Vol. 54, 2017, pp. 1664-1674.(doi:10.2514/1.C034156)

[28] Demasi, L., Monegato, G., and Cavallaro, R., "Minimum Induced Drag Theorems for Multiwing Systems,” AIAA Journal, Vol. 55, 2017, pp. 3266-3287.(doi:10.2514/1.J055652)

[29] Noll, T. E., Ishmael, S. D., Henwood, B., Perez-Davis, M. E., Tiffany, G. C., Madura, J., Gaier, M., Brown, J. M., and Wierzbanowski, T., "Technical Findings, Lessons Learned, and Recommendations Resulting from the Helios Prototype Vehicle Mishap," NATO/RTO AVT-145 Workshop on Design Concepts, Processes, and Criteria for UAV Structural Integrity, Florence, Italy, 14-18 May, 2007.

[30] Vos, R., Gurdal, Z., and Abdalla, M., "Mechanism for Warp-Controlled Twist of a Morphing Wing," Journal of Aircraft, Vol. 47, No. 2, March-April, 2010, pp. 450-457.(doi:10.2514/1.39828)

[31] Joo, J., Marks, C., Zientarski, L., and Culler, A., "Variable Camber Compliant Wing - Design," AIAA-2015-1050, 23 rd AIAA/AHS Adaptive Structures Conference, Kissimmee, Florida, 5-9 January 2015. 
[32] Marks, C. R., Zientarski, L., Culler, A. J., Hagen, B., Smyers, B. M., and Joo, J. J., "Variable Camber Compliant Wing Wind Tunnel Testing”, AIAA 2015-1051, 23rd AIAA/AHS Adaptive Structures Conference, Kissimmee, Florida, 5-9 January, 2015.

[33] Miller, S. C., Rumpfkeil, M. P., and Joo, J. J., "Fluid-Structure Interaction of a Variable Camber Compliant Wing," AIAA-2015-1235, 53 ${ }^{\text {rd }}$ AIAA Aerospace Sciences Meeting, Kissimmee, Florida, 5-9 January 2015.

[34] Joo, J. J., Marks, C. R., and Zientarski, L., “Active Wing Shape Reconfiguration using a Variable Camber Compliant Wing System," 20 th International Conference on Composite Materials, Copenhagen, Denmark, 19-24 July 2015.

[35] Marks, C. R., Zientarski, L., and Joo, J. J., "Investigation into the Effect of Shape Deviation on Variable Camber Compliant Wing Performance," AIAA-2016-1313, 24 ${ }^{\text {th }}$ AIAA/AHS Adaptive Structures Conference, San Diego, California, 4-8 January 2016.

[36] Alley, N. R., Phillips, W. F., and Spall, R. E., "Predicting Maximum Lift Coefficient for Twisted Wings Using Computational Fluid Dynamics,” Journal of Aircraft, Vol. 44, No. 3, 2007, pp. 911-917.(doi:10.2514/1.25643)

[37] Vernengo, G., Bonfiglio, L., and Brizzolara, S., "Supercavitating Three-Dimensional Hydrofoil Analysis by Viscous Lifting-Line Approach,” AIAA Journal, Vol. 55, No. 12, 2017, pp. 4127-4141.(doi:10.2514/1.J055504)

[38] Gamble, L. L., Pankonien, A. M., and Inman, D. J., "Stall Recovery of a Morphing Wing via Extended Nonlinear LiftingLine Theory," AIAA Journal, Vol. 55, No. 9, 2017, pp. 2956-2963.(doi:10.2514/1.J055042)

[39] Izraelevitz, J. S., Zhu, Q., and Triantafyllou, M. S., "State-Space Adaptation of Unsteady Lifting Line Theory: Twisting/Flapping Wings of Finite Span,” AIAA Journal, Vol. 55, No. 4, 2017, pp. 1279-1294.(doi:10.2514/1.J055144)

[40] Gallay, S., and Laurendeau, E., "Preliminary-Design Aerodynamic Model for Complex Configurations Using Lifting-Line Coupling Algorithm," Journal of Aircraft, Vol. 53, No. 4, 2016, pp. 1145-1159.(doi:10.2514/1.C033460)

[41] Gallay, S., and Laurendeau, E., "Nonlinear Generalized Lifting-Line Coupling Algorithms for Pre/Poststall Flows," AIAA Journal, Vol. 53, No. 7, 2015, pp. 1784-1792.(doi:10.2514/1.J053530)

[42] Spalart, P. R., "Prediction of Lift Cells for Stalling Wings by Lifting-Line Theory," AIAA Journal, Vol. 52, No. 8, 2014, pp. 1817-1821.(doi:10.2514/1.J053135)

[43] Phillips, W. F., “Analytical Decomposition of Wing Roll and Flapping Using Lifting-Line Theory," Journal of Aircraft, Vol. 51, No. 3, 2014, pp. 761-778.(doi:10.2514/1.C032399)

[44] Phillips, W. F., and Hunsaker, D. F., "Lifting-Line Predictions for Induced Drag and Lift in Ground Effect," Journal of Aircraft, Vol. 50, No. 4, 2013, pp. 1226-1233.(doi:10.2514/1.C032152)

[45] Wickenheiser, A. M., and Garcia, E., "Extended Nonlinear Lifting-Line Method for Aerodynamic Modeling of Reconfigurable Aircraft," Journal of Aircraft, Vol. 48, No. 5, 2011, pp. 1812-1817.(doi:10.2514/1.C031406)

[46] Junge, T., Gerhardt, F. C., Richards, P., and J. Flay, R. G., “Optimizing Spanwise Lift Distributions Yacht Sails Using Extended Lifting Line Analysis,” Journal of Aircraft, Vol. 47, No. 6, 2010, pp. 2119-2129.(doi:10.2514/1.C001011)

[47] Wickenheiser, A., and Garcia, E., “Aerodynamic Modeling of Morphing Wings Using an Extended Lifting-Line Analysis,” Journal of Aircraft, Vol. 44, No. 1, 2007, pp. 10-16.(doi:10.2514/1.18323)

[48] Sugimoto, T., "Induced Velocity in the Plane of an Elliptically Loaded Lifting Line," AIAA Journal, Vol. 40, No. 6, 2002, pp. 1233-1236.(doi:10.2514/2.1776) 
[49] Phillips, W. F., and Snyder, D. O., "Modern Adaptation of Prandtl's Classic Lifting-Line Theory," Journal of Aircraft, Vol. 37, No. 4, 2000, pp. 662-670.(doi:10.2514/2.2649)

[50] Rasmussen, M. L., and Smith, D. E., "Lifting-Line Theory for Arbitrarily Shaped Wings," Journal of Aircraft, Vol. 36, No. 2, 1999, pp. 340-348.(doi:10.2514/2.2463)

[51] Iosilevskii, G., "Lifting-line theory of an arched wing in asymmetric flight," Journal of Aircraft, Vol. 33, No. 5, 1996, pp. 1023-1026.(doi:10.2514/3.47050)

[52] Jadic, I., and Constantinescu, V. N., "Lifting line theory for supersonic flow applications," AIAA Journal, Vol. 31, No. 6, 1993, pp. 987-994.(doi:10.2514/3.11718)

[53] Plotkin, A., and Tan, C. H., "Lifting-line solution for a symmetrical thin wing in ground effect," AIAA Journal, Vol. 24, No. 7, 1986, pp. 1193-1194.(doi:10.2514/3.9413)

[54] Cheng, H. K., Meng, S. Y., Chow, R., and Smith, R. C., "Transonic swept wings studied by the lifting-line theory," AIAA Journal, Vol. 19, No. 8, 1981, pp. 961-968.(doi:10.2514/3.7837)

[55] Anderson, J. D., and Corda, S., "Numerical lifting line theory applied to drooped leading-edge wings below and above stall," Journal of Aircraft, Vol. 17, No. 12, 1980, pp. 898-904.(doi:10.2514/3.44690)

[56] Cheng, H. K., and Meng, S. Y., "Lifting-Line Theory of Oblique Wings in Transonic Flows," AIAA Journal, Vol. 17, No. 1, 1979, pp. 121-124.(doi:10.2514/3.61081)

[57] Cheng, H. K., "Lifting-Line Theory of Oblique Wings," AIAA Journal, Vol. 16, No. 11, 1978, pp. $1211-1213$. (doi:10.2514/3.61033)

[58] Small, R. D., "Transonic lifting line theory - Numerical procedure for shock-free flows," AIAA Journal, Vol. 16, No. 6, 1978, pp. 632-634.(doi:10.2514/3.7562)

[59] Lan, C. E., and Fasce, M. H., “Applications of an improved nonlinear lifting-line theory," Journal of Aircraft, Vol. 14, No. 4, 1977, pp. 404-407.(doi:10.2514/3.44601)

[60] Bera, R. K., "Comment on "Solution of the Lifting Line Equation for Twisted Elliptic Wings"," Journal of Aircraft, Vol. 12, No. 6, 1975, pp. 561-562.(doi:10.2514/3.59834)

[61] Bera, R. K., "Some remarks on the solution of the lifting line equation," Journal of Aircraft, Vol. 11, No. 10, 1974, pp. 647-648.(doi:10.2514/3.44397)

[62] Lan, C. T., "An improved nonlinear lifting-line theory." AIAA Journal, Vol. 11, No. 5, 1973, pp. 739-742. (doi:10.2514/3.6819)

[63] Kerney, K. P., “A correction to 'lifting-line theory as a singular perturbation problem., ,’ AIAA Journal, Vol. 10, No. 12, 1972,pp. 1683-1684.(doi:10.2514/3.6702)

[64] Filotas, L. T., "Solution of the lifting line equation for twisted elliptic wings," Journal of Aircraft, Vol. 8, No. 10, 1971, pp. 835-836.(doi:10.2514/3.44308).

[65] Lakshminarayana, B., "Extension of lifting-line theory to a cascade of split aerofoils," AIAA Journal, Vol. 2, No. 5, 1964, pp. 938-940.(doi:10.2514/3.2461)

[66] Anderson, R. C., and Millsaps, K., "Application of the galerkin method to the prandtl lifting line equation," Journal of Aircraft, Vol. 1, No. 3, 1964, pp. 126-128.(doi:10.2514/3.43565) 
[67] Tuyl, A. V., “The Replacement of Lifting Surfaces by Lifting Lines with Variable Position,” Journal of the Aerospace Sciences, Vol. 26, No. 2, 1959, pp. 127-128.(doi:10.2514/8.7967)

[68] Dengler, M. A., "Concerning "The Subsonic Calculation of Circulatory Spanwise Loadings for Oscillating Airfoils by Lifting-Line Techniques"," Journal of the Aeronautical Sciences, Vol. 20, No. 6, 1953, pp. 439-439.(doi:10.2514/8.2673)

[69] Dengler, M. A., "The Subsonic Calculation of Circulatory Spanwise Loadings for Oscillating Airfoils by Lifting-Line Techniques," Journal of the Aeronautical Sciences, Vol. 19, No. 11, 1952, pp. 751-759.(doi:10.2514/8.2459)

[70] Reissner, E., "Note on the Relation of Lifting-Line Theory to Lifting-Surface Theory," Journal of the Aeronautical Sciences, Vol. 18, No. 3, 1951, pp. 212-214.(doi:10.2514/8.1905)

[71] Flax, A. H., "On a Variational Principle in Lifting-Line Theory," Journal of the Aeronautical Sciences, Vol. 17, No. 9, 1950, pp. 596-597.(doi:10.2514/8.1732)

[72] Thomas, F., “Appendix 1: Sailplane Design Data and Drawings,” Fundamentals of Sailplane Design, Translated by J. Milgram, College Park Press, College Park, MD, 1999, pp. 195-244.

[73] Stewart, A. J., and Hunsaker, D. F., “ Minimization of Induced and Parasitic Drag on Variable-Camber Morphing Wings,” AIAA-2020-0277, AIAA Scitech 2020 Forum, Orlando, Florida, 6-10 January, 2020.(doi:10.2514/6.2020-0277)

[74] “Boeing 777 Airplane Rescue and Fire Fighting Information,” Boeing Commercial Airplanes, October, 2018.

[75] “777-200/300 Airplane Characteristics for Airport Planning”, D6-58329, Boeing Commercial Airplanes, July, 1998.

[76] Langton, R., Clark, C., Hewitt, M., and Richards, L., "Fuel System Functions of Commercial Aircraft," Aircraft Fuel Systems, Wiley, Hoboken, NJ, 2009, pp. 53-95.(doi: 10.1002/9780470059470) 